University of Zurich

Department of Economics

Working Paper Series

ISSN 1664-7041 (print)

ISSN 1664-705X (online)

Working Paper No. 261

\title{
Frictional Asset Reallocation under Adverse Selection
}

Florian Madison

Revised version, January 2018 


\title{
Frictional Asset Reallocation under Adverse Selection*
}

\author{
Florian Madison ${ }^{\dagger}$ \\ University of California, Irvine and University of Basel
}

January 24, 2018

\begin{abstract}
The aim of this paper is to study asset reallocation in financial markets subject to search, bargaining, and information frictions, and to analyze the impact of monetary policy on equilibrium outcomes. The main results show that private information regarding the quality of an asset impairs its liquidity and reduces both trading volume and consumption. As a consequence, a positive liquidity differential between money and real assets emerges, resulting in an increased demand for fiat money, as observed since the eruption of the global financial crisis. A policy intervention replacing information sensitive assets with government bonds or fiat money, as done in the asset-purchase program implemented by the Federal Reserve Bank, improves welfare.
\end{abstract}

JEL Classification: D82, D83, E44, E52, G11, G12

Keywords: money, assets, search and matching, asymmetric information, signaling, undefeated equilibrium

\footnotetext{
*I would like to thank Aleksander Berentsen and Guillaume Rocheteau for their extensive support and helpful comments during this project. Special thanks also go to William Branch, Francesca Carapella, Paul Jackson, Mohammed Aït Lahcen, and Lukas Altermatt for our fruitful conversations at the University of Basel and the University of California, Irvine. Moreover, the paper has benefited from the participants of the Third African Search and Matching Workshop in Morocco and the reading groups at the department for economic theory at the University of Basel, and at the economics department at the University of California, Irvine. Earlier working title: Monetary Policy, Asset Prices, and Liquidity under Adverse Selection.

$\dagger$ Email: flomadison@gmail.com
} 


\section{Introduction}

Assets have always been valued for their liquidity properties. First and foremost, fiat money. Its inherited characteristics including durability, portability, recognizability, and the low risk of being counterfeited allow it to provide superior insurance services in times of unforeseen liquidity needs. Due to nominal frictions, this insurance comes at a cost, as addressed early on by Hicks (1935) in his work on the rate-of-return dominance puzzle, and Tobin (1965), analyzing the relationship between asset prices and monetary policy. However, money is not the only asset considered liquid these days. Depending on the consumption and investment opportunities an individual or an institution plans to seize in the future, different media of exchange find acceptance, resulting in dispersion in the demand for different assets.

Besides its fundamentals, the liquidity of an asset usually depends on the environment encountered. While financial markets generally allow you to use any asset as means of payment, as studied by Geromichalos et al. (2007) and Lagos (2010), in other markets, the opportunity costs are higher, since transactions are required to be settled in fiat money (see e.g. Lagos and Wright (2005)). Secondary financial markets can remedy this cost by allowing for portfolio reallocation. In other words, they enable storing wealth in profitable assets and liquidating the appropriate portion whenever a consumption opportunity requiring a monetary payment comes up. Gains from trade emerge from individual liquidity needs, i.e., different idiosyncratic ex-post valuations for a particular asset. At what cost this reallocation takes place is determined by the characteristics of the market traded in. While money and assets can be considered perfect substitutes in frictionless centralized markets, inefficiencies can arise from decentralization. Among the first to depart from the assumption of complete markets to study search and bargaining frictions in decentralized secondary asset markets were Duffie et al. (2005), later generalized to an environment with perfectly divisible assets by Lagos and Rocheteau (2009). Nominal frictions and monetary policy were first added by Lagos and Zhang (2015) and Geromichalos and Herrenbrueck (2016), where in the latter trade on secondary markets occurs based on idiosyncratic liquidity shocks. A trading motive I will resort to in this work.

The events of the last decade has revealed another important friction: private information. As documented by Gorton and Metrick (2012) and Gorton and Ordoñez (2014), with the eruption of the global financial crisis in 2007, certain asset classes switched from being information-insensitive to information-sensitive. As a result of that, the notion of asset liquidity had to take into account the effect of information frictions, since the increased

opacity regarding the quality of an asset directly impacted the acceptability of these assets 
as a medium of exchange. Consequentially, in order to be able to maintain a desired consumption level, financial institutions abstained from the acquisition of such securities and adjusted their portfolio towards more liquid asset classes, such as fiat money and treasury bonds. Lower trading volume on secondary markets was the consequence. ${ }^{1}$

Taking the implications of search, bargaining, and information frictions seriously, the aim of this paper is to study the relationship between portfolio accumulation in the primary market and reallocation in the secondary market. The baseline model is a variant of the infinite-time search-theoretic dynamic general equilibrium model established by Lagos and Wright (2005), extended by an exogenous supply of real assets and an over-the-counter secondary asset market along the lines of Geromichalos and Herrenbrueck (2016). Under uncertainty regarding an upcoming consumption opportunity, agents choose a portfolio consisting of fiat money and one-period lived Lucas (1978) trees, whereas only fiat money is accepted as medium of exchange to purchase consumption goods. After being informed about their individual liquidity needs, agents can then enter a secondary market to readjust their portfolio with the drawback of search, bargaining, and information frictions.

In a first step, I establish a benchmark economy without private information along the lines of Geromichalos and Herrenbrueck (2016). The results show that under the Friedman rule, agents carry enough money along the period, and thus trade on a secondary market becomes obsolete. Once the nominal interest rate deviates from the Friedman rule, however, there are gains from reallocation, relaxing a consumer's liquidity constraint in the goods market, similar to financial intermediaries in Berentsen et al. (2007). Crucial for the resulting equilibrium allocations is the aggregate amount of money and assets held in a bilateral match. If money and assets are plentiful, assets trade at their fundamental value in the primary market. With increased scarcity, an indirect liquidity premium emerges, increasing the primary market price of real assets. ${ }^{2}$ This is the channel through which monetary policy is able to affect an agent's initial portfolio choice, and thus trading volume on secondary markets. The size of the liquidity premium further depends on the ex-ante uncertainty regarding a future consumption opportunity, and vanishes with increased matching frictions in the secondary market.

\footnotetext{
${ }^{1}$ There is a broad range of literature analyzing cash hoarding behavior on the financial markets in the aftermath of the global financial crisis. While some authors predominantly focus on the financial markets in the United States - see Caballero and Krishnamurthy (2008), Acharya et al. (2011), Acharya and Skeie (2011), Bolton et al. (2011), Diamond and Rajan (2011), Gale and Yorulmazer (2013), and Berentsen and Müller (2015) - Heider et al. (2015), Ashcraft et al. (2011), and Acharya and Merrouche (2012) in turn analyze its spread to the Euro area towards the end of 2011.

${ }^{2}$ I refer to the liquidity premium as indirect, since contrary to frameworks where money and assets compete as a medium of exchange, the premium here emerges indirect through trade on the secondary market. Relevant work analyzing direct liquidity premia involves Geromichalos et al. (2007), Lagos and Rocheteau (2008), Lagos (2010, 2011), Rocheteau (2011), Lester et al. (2012), and Jacquet and Tan (2012).
} 
Having established the benchmark scenario under complete-information, I then extend the developed model by introducing private information regarding the assets' stochastic future return. In order to do so, I apply a signaling game, refined by the Mailath et al. (1993) undefeated equilibrium to endogenize the choice between a pooling and a separating offer, eliminating Pareto inefficiencies. The general results show that information frictions impair the liquidity of a real asset on the secondary market and reduce consumption. In a separating equilibrium, high-quality asset-holders distinguish themselves from low-quality asset-holders by asset retention, along the lines of Demarzo and Duffie (1999) and Rocheteau (2011), whereas the amount of assets a high-quality asset-seller needs to hold back depends on monetary policy and the severity of the information friction in the economy. The larger the difference between the return of a low and a high quality asset, the tighter the incentive compatibility constraint and thus the lower the amount of assets sold by the high-type. In a pooling equilibrium, however, assets are sold at the expected value, which resembles a tax on consumption of the high-quality asset seller. Thus, in order to alleviate this burden, he chooses to sell a lower quantity, resulting in reduced consumption. Analogue to the separating equilibrium, the amount of assets sold depends on the degree of private information and current monetary policy.

The general equilibrium structure of the framework allows capturing the effects of the aforementioned frictions in the secondary market on an agent's optimal portfolio choice in the primary market, enabling a detailed analysis of the liquidity premia and the liquidity structure of money and real assets. The results show that contrary to the benchmark economy with complete information, the demand for fiat money is not only determined by the current monetary regime. Instead, under private information, fiat money incorporates a positive liquidity premium, since an additional unit relaxes a high-type's incentive compatibility constraint, and thus enables him to consume more in the cash-only goods market. As a result, even in the absence of matching frictions in the secondary market, a positive rate-of-return differential between money and assets emerges, whereas fiat money inherits a higher liquidity value than real assets. Both liquidity premia, as well as the liquidity differential, decrease with an increase in the agent's money holdings. Hence, monetary policy interventions leading to an increase in the value of fiat money enable the monetary authority to narrow the rateof-return differential and improve equilibrium allocations. A policy along the lines of Tirole (2012), replacing information-sensitive assets with fiat money or real bonds, as done in the asset-purchase program implemented by the Federal Reserve Bank, would decrease the costs associated to information frictions and improve equilibrium consumption and overall welfare. 


\section{$1.1 \quad$ Related Literature}

When analyzing the relationship between asset prices and monetary policy, a broad literature exists, finding its origin in the work of Tobin (1965) on 'money and economic growth'. Since then, monetary economics has studied different variations of asset markets, whereas Geromichalos et al. (2007) and Lagos (2010) were among the first to elaborate on the effect of monetary policy on asset prices in an environment characterized by search and bargaining frictions.

This paper contributes to the vast literature on asset reallocation. The cornerstone is the framework established by Duffie et al. (2005), in which agents hold one unit of an indivisible asset and exchange it against transferable utility on over-the-counter markets characterized by search and bargaining frictions. Gains from trade emerge from different idiosyncratic valuations for the asset held. Lagos and Rocheteau (2009) generalize this framework to an environment with perfectly divisible assets, allowing them to determine key dimensions of market liquidity, such as bid-ask spreads, trade volume, and trading delays. A first extension of Duffie et al. (2005) to incorporate dealers' inventories was provided by Weill (2007), whereas Lagos et al. (2011) later combined indivisible assets and dealers' inventories to study a dealer's response to a crash and stochastic recovery. The first abstaining from the exchange of transferable utility in these markets were Lagos and Zhang (2015) by introducing monetary exchange, whereas the trading motive is still driven by different valuations for the asset held. Environments in which trade takes place based on idiosyncratic liquidity shocks are provided by Geromichalos and Herrenbrueck (2016), Mattesini and Nosal (2016) and Trejos and Wright (2016), whereas the first can be considered the benchmark framework. Mattesini and Nosal (2016) in turn focus on the role of dealers in over-the-counter markets, while Trejos and Wright (2016) embed this structure into a second-generation model with indivisible assets, following Shi (1995) and Trejos and Wright (1995). However, none of these models explicitly study the interplay of monetary policy and asymmetric information, and its effect on asset prices, optimal portfolio choice, and asset reallocation in an economy characterized by search and bargaining frictions.

When studying the relationship between asset prices and asymmetric information, current literature relies on the influential work of Akerlof (1970), Rothschild and Stiglitz (1976), Wilson (1980), Burdett and Judd (1983), and Eisfeldt (2004). Among the first to study the effect of adverse selection on cash holdings during the financial crisis were Bolton et al. (2011), comparing the use of inside versus outside liquidity to finance a consumption opportunity. In their framework, using a origination-and-contingent-distribution model of banking, 
they show that although outside liquidity dominates inside liquidity under full information, the presence of private information regarding the quality of the outside liquidity can lead to early asset liquidation and excessively high cash-holdings. Malherbe (2014) provides a similar result, where cash hoarding and secondary market breakdown emerge under private information due to self-fulfilling beliefs. The resulting market illiquidity promotes higher cash holdings and thus justifies the initial beliefs. ${ }^{3}$ While Malherbe (2014) only considers pooling equilibria in competitive markets, Guerrieri and Shimer (2014) use a competitive search model with indivisible assets along the lines of Guerrieri et al. (2010), allowing for separating equilibria. Their results show that increased private information regarding the quality of a financial asset can cause fire sales and a flight to quality. Chiu and Koeppl (2016), in turn, consider bilateral trade in an asset market with asymmetric information, where finding a trading partner takes time. They show that different valuations for assets allow for pooling equilibria, and that the government can resurrect trading by a one-shot purchase. Lauermann and Wolinsky (2016) analyze the effects of adverse selection in a model with sequential search. A study of two-dimensional asymmetric information in a competitive search model is provided by Chang (2017) and Williams (2016). In these frameworks, agents are not only privately informed about the quality of the asset they are holding, but also their private distress position. While Chang (2017) focuses on semi-pooling equilibria using probabilistic retention and indivisible assets, Williams (2016) introduced divisible assets and established full separation using a combination of probabilistic retention and asset retention. An experimental study on how informational frictions affect trading in decentralized markets is provided by Berentsen et al. (2017).

Regarding the equilibrium refinement, Li and Rocheteau (2008), Bajaj (2016) and Madison (2017) were amongst the first to apply the Mailath et al. (1993) undefeated equilibrium to a monetary-search model, allowing for pooling and separating equilibria to coexist. In doing so, Li and Rocheteau (2008) consider a second generation model with indivisible assets along the lines of Shi (1995) and Trejos and Wright (1995) to study counterfeiting equilibria. Bajaj (2016) revisits this framework, but instead focuses on the coexistence of bonds and real assets subject to private information. Madison (2017) in turn applies the undefeated equilibrium to a third generation model à la Lagos and Wright (2005) and Rocheteau (2011) to compare asset sale and collateralized credit under private information, refuting equivalence.

Concerning the organization of the paper, Section 2 outlines the environment of the model and solves the bargaining games in the different markets. The optimal portfolio choice of an

\footnotetext{
${ }^{3} \mathrm{~A}$ similar result has been established by Morris and Shin (2012), where even a small amount of adverse selection can lead to a market breakdown due to a loss of market confidence. This allows them to discuss the role of contagious adverse selection and the problem of toxic assets in the recent financial crisis.
} 
agent in the primary market is described in Section 3. Using these insights, Section 4 discusses different policy measures to overcome the problem of adverse selection, while Section 5 concludes.

\section{Model}

\subsection{Environment}

Consider a dynamic general equilibrium model based on the unified search-theoretic framework established by Lagos and Wright (2005) and the extensions introduced by Geromichalos and Herrenbrueck (2016). Time is discrete, starts at $t=0$, and continues forever. Each period is divided into three subperiods: a centralized primary market, a decentralized secondary market, and a centralized goods market. The discount factor across periods is $\beta=(1+r)^{-1}$ and $r>0$ is the rate at which agents discount future utility. There is a continuum $[0,1]$ of infinitely lived agents with an expected lifetime utility from date $t=0$ onwards defined as:

$$
\mathbb{E} \sum_{t=0}^{\infty} \beta^{t}\left[u\left(q_{t}\right)-c\left(q_{t}\right)+U\left(x_{t}\right)-h_{t}\right],
$$

with $q$ being the consumption good in the goods market, $x$ the numéraire good in the primary market, and $h$ the hours worked in the primary market. For tractability, the period utility is separable across subperiods. The utility function in the goods market, $u(q)$, is twice continuously differentiable, strictly increasing in $q$ and concave, $u^{\prime}(q)>0>u^{\prime \prime}(q)$, fulfilling the Inada (1963) conditions. ${ }^{4}$ The disutility of production in the goods market is linear, $c(q)=q$. In the primary market, utility of consumption, $U(x)$, and disutility of production are both linear with labor being the only input, $h=x$. In the following, the timing of events and the three markets are discussed in detail, starting with the primary market (see Figure 1).

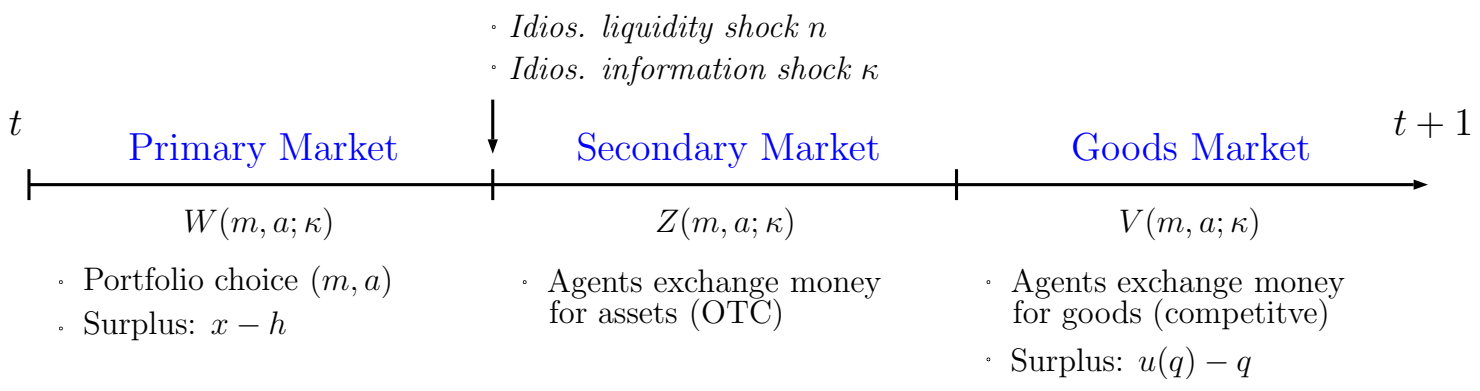

Figure 1: Timing of Events

\footnotetext{
${ }^{4}$ The value of the function at $q=0$ is zero, the limit of the derivative towards zero is positive infinity, $u^{\prime}(0)=\infty$, and the limit of the derivative towards infinity is zero, $u^{\prime}(\infty)=0$.
} 
Primary Market: All agents produce and consume a numéraire good, $x$, and adjust their portfolios consisting of perfectly divisible fiat money, $m \in \mathbb{R}_{+}$, and perfectly divisible oneperiod lived real assets, $a \in \mathbb{R}_{+}$, whereas $M_{t} \in \mathbb{R}_{+}$and $A_{t} \in \mathbb{R}_{+}$is the total stock of money and assets in the economy, respectively, and $\phi_{t}$ and $\varphi_{t}$ are the corresponding primary market prices. While fiat money is portable, storable, recognizable by all agents, and thus perfectly liquid, real assets are intangible and therefore illiquid, i.e., not accepted as a direct means of payment in the goods market. ${ }^{5}$

Secondary Market: At the beginning of the second subperiod, two idiosyncratic shocks realize. First, each agent is privately informed about the terminal real return of his oneperiod lived asset. The realization of the shock is common to all assets held by an agent, but independent across agents, following the logic of Plantin (2009). I impose a stochastic return in real goods, $\kappa \geq 0$, which can take on two values, $0 \leq \kappa^{L} \leq \kappa^{H} \leq \infty$, similar to the fruits of a Lucas (1978) tree. With probability $\pi^{H} \equiv \operatorname{Prob}\left[\kappa=\kappa^{H}\right]$, the investment succeeds and yields a terminal return $\kappa=\kappa^{H}$, while with the complementary probability, $\pi^{L} \equiv 1-\pi^{H}$, it fails with $\kappa=\kappa^{L}$. For simplicity, the expected return is normalized to one, i.e., $R=\pi^{H} \kappa^{H}+\pi^{L} \kappa^{L}=1$.

Second, each agent learns his role in the goods market. With probability $n \in(0,1)$, agents want to produce, but cannot consume the search good $q$, while with complementary probability, $1-n$, agents want to consume, but cannot produce. From here onwards, I will refer to consumers in the goods market as 'buyers' and to producers as 'sellers'. The subscripts $b$ and $s$ denote these two roles respectively. For simplicity, the role of an agent in the goods market is public information, allowing us to abstain from forming beliefs regarding the motive for trading in the secondary market. ${ }^{6}$

Having learned their role in the goods market and thus their end-of-day money demand, agents enter a over-the-counter asset market à la Duffie et al. (2005) and Lagos and Zhang (2015) to readjust their portfolio. The ex-post heterogeneity allows for gains from trade to be realized. Matching is bilateral and random, with $\alpha(n) \leq \min \{n, 1-n\}$ being the probability of finding a trading partner, conditional on the distribution of buyers and sellers in the economy. Nash bargaining under private information determines the terms of trade.

Goods Market: In the last subperiod, agents trade fiat money, $m$, against search goods, $q$, in a perfectly competitive market. All market participants and trades are anonymous,

\footnotetext{
${ }^{5}$ See Berentsen and Monnet (2008) and Berentsen et al. (2014).

${ }^{6}$ If the trading motive in the secondary market was private information, another layer of beliefs would be added. As a result, a maximization problem with two-dimensional asymmetric information emerges, similar to the ones elaborated by Chang (2017) and Williams (2016).
} 
lack commitment, and trading histories are private information, which precludes unsecured credit between buyers and sellers. Given there is a double coincidence of wants problem, a medium of exchange (fiat money) for direct settlement is essential for trade to occur, as shown by Kocherlakota (1998), Wallace (2001) and Shi (2006).

Monetary Policy: There is a central bank managing the money supply in the economy according to:

$$
M_{t+1}=M_{t}+T
$$

where $M_{t}$ denotes the per capita money stock at the beginning of period $t$ and $T \equiv \tau M_{t}$ are lump-sum transfers conducted by the central bank. One unit of money can buy $\phi$ units of the general good in the primary market. Since we focus on symmetric and stationary monetary equilibria, where all agents follow identical strategies and real balances are constant over time, i.e., $\phi_{t+1} M_{t+1}=\phi_{t} M_{t}$, it holds that:

$$
\frac{M_{t+1}}{M_{t}}=\frac{\phi_{t}}{\phi_{t+1}}=\gamma
$$

with $\gamma$ being the growth rate of the money supply.

Social Optimum: The expected lifetime utility of a representative agent for a stationary allocation, $(m, a)$, is given by:

$$
(1-\beta) W=\left[(1-n) u\left(q_{b}\right)-n q_{s}\right]+(\beta R-\varphi) a
$$

While the first term on the right-hand side of (4) denotes the expected utility from consuming and producing in the goods market, the second term represents the net benefit of purchasing assets and receiving the discounted expected return, $\beta R$, in the primary market of the subsequent period $t+1$. Since all agents enter the period with the same amount of assets, $q_{b}$ and $q_{s}$ are the same for all of them. By market clearing, it is straightforward to show that $q_{s}=\frac{1-n}{n} q_{b}$.

Solving the planner's problem, the first-best allocation, $\left(q^{*}, a^{*}\right)$, satisfies $q=q^{*}$, where $u^{\prime}\left(q^{*}\right)=1$. Hence, at the optimum, the marginal utility of consumption in the goods market, $u^{\prime}\left(q^{*}\right)$, equals the marginal cost of production, 1 . Concerning the asset, from a planner's perspective, $a^{*}=0$ if $\beta R<\varphi$, and $a^{*} \in[0, \infty]$ is indeterminate if $\beta R=\varphi$. Hence, if assets are costly to hold, a social planner would never choose to carry a positive amount from the primary into the secondary market. ${ }^{7}$

\footnotetext{
${ }^{7}$ If $\beta R<\varphi$, acquiring real assets is a social waste. Hence, real assets would have no use in this economy from a planner's point of view, although individually they can facilitate trade.
} 
Having determined the physical environment of the economy, we will now analyze the terms of trade and equilibrium outcomes in the different markets. I proceed by backward induction, starting with the primary market. Without loss of generality, it is assumed that the composition of the agents' portfolio is common knowledge in the match, which allows to ignore the formation of beliefs regarding money and asset holdings, and thus simplifies the analysis of the bargaining game.

\subsection{Primary Market}

The utility of an agent entering the primary market with $m \in \mathbb{R}_{+}$units of money and $a \in \mathbb{R}_{+}$ units of real assets is:

$$
\begin{aligned}
W(m, a ; \kappa) & =\max _{x, h, m^{\prime}, a^{\prime}} x-h+\mathbb{E} Z\left(m^{\prime}, a^{\prime} ; \kappa^{\prime}\right) \\
\text { s.t. } & x+\phi m^{\prime}+\varphi a^{\prime}=h+a \kappa+\phi m+T,
\end{aligned}
$$

where an agent finances his goods consumption, $x$, and his end-of-period money and asset balances, $m^{\prime}$ and $a^{\prime}$, through inputs of labor, $h$, lump-sum transfers, $T$, fiat money, $\phi m$, and asset returns, $a \kappa$, remaining from last period. $Z\left(m^{\prime}, a^{\prime} ; \kappa^{\prime}\right)$ is the secondary market value function, where the expected value, $\mathbb{E}$, corresponds to the uncertainty regarding the terminal return of the asset and the money demand in the goods market. Using the agent's budget constraint to eliminate $x-h$ in the objective function, the following first-order conditions emerge:

$$
\begin{array}{ll}
\mathbb{E} Z_{m^{\prime}} \leq \phi & \left(=\text { if } m^{\prime}>0\right) \\
\mathbb{E} Z_{a^{\prime}} \leq \varphi & \left(=\text { if } a^{\prime}>0\right),
\end{array}
$$

where $\mathbb{E} Z_{m^{\prime}}$ and $\mathbb{E} Z_{a^{\prime}}$ are the marginal values of taking another unit of fiat money and real assets into the secondary market. Since the marginal disutility of working in the primary market is $1,-\phi$ and $-\varphi$ are the utility costs of acquiring one unit of money and assets in the primary market, respectively. The implication of (7) is that agents all enter the secondary market with the same portfolio, $(m, a)$. The envelope conditions are:

$$
W_{m}=\phi ; \quad W_{a}=\kappa
$$

where $W_{i}$ is the partial derivative of $W(m, a ; \kappa)$ with respect to $m$ and $a$. Given the quasilinear preferences, $W(m, a ; \kappa)$ is linear in wealth and the agents' portfolio choice for the subsequent goods market, $m^{\prime}$ and $a^{\prime}$, is independent of the current holdings, $m$ and $a$, when 
entering the market.

\subsection{Goods Market}

The respective lifetime utility of a buyer and a seller entering the goods market with $m$ units of money and $a$ units of assets is:

$$
\begin{aligned}
& V_{b}\left(m, a ; \kappa_{b}\right)=u(q)+\beta W\left(m-d, a ; \kappa_{b}\right) \\
& V_{s}\left(m, a ; \kappa_{s}\right)=-q+\beta W\left(m+d, a ; \kappa_{s}\right),
\end{aligned}
$$

where $d$ is the monetary transfer from a buyer to a seller. Given the goods market is perfectly competitive, buyers' and sellers' problems are solved independently. A seller maximizes:

$$
\left(q_{s}, d_{s}\right) \in \arg \max _{q, d}-q+\beta W\left(m+d, a ; \kappa_{s}\right) .
$$

Given (11), sellers produce until the marginal costs are equal to the relative price of goods across markets, i.e., $\beta \phi=1$. Hence, $q_{s}$ is independent of the seller's money and asset holdings, $m$ and $a$, and therefore, a seller produces the same amount of goods, no matter his financial decisions in the previous two markets. If an agent is a buyer, he faces the following problem:

$$
\begin{gathered}
\left(q_{b}, d_{b}\right) \in \underset{q, d}{\arg \max _{\text {ax }}} \quad u(q)+\beta W\left(m-d, a ; \kappa_{b}\right) \\
\text { s.t. } \quad m \geq d,
\end{gathered}
$$

subject to a no-debt constraint with the corresponding Lagrange multiplier, $\beta \phi \theta$. The firstorder condition, using the market-clearing condition, $q_{b}=q_{s}$, combined with (8), is:

$$
u^{\prime}(q)=1+\theta
$$

Definition A. An equilibrium in the competitive goods market is a pair of strategies, $(q, d)$, such that the terms of trade, $(q, d)$, are a solution to the seller's and the buyer's maximization problem, (11) and (12).

Lemma A. The equilibrium allocations to the goods market problems, (11) and (12), are:

$$
q=\min \left\{q^{*}, \beta \phi m\right\}
$$

The competitive solution to the buyer's and seller's problem is $q(d)=\beta \phi \min \left\{d^{*}, d\right\}$, where $d^{*}=\frac{q^{*}}{\beta \phi}$ is the amount of money, given today's value of money, $\phi$, that allows a buyer to 
purchase the socially-efficient quantity, $q^{*}$. Proof in Appendix A.

According to (14), a buyer consumes the socially-efficient quantity, $\beta \phi m^{*}=q^{*}$, if his fiat money holdings are large enough to compensate the seller for the disutility to produce. In other words, if the buyer brings enough money into the goods market, $m \geq m^{*}$, the no-debt constraint is non-binding, $\theta^{N}=0$, and (13) reduces to $u^{\prime}(q)=1$. However, if $m<m^{*}$, consumption is inefficiently low, $q<q^{*}$, and there are gains from trade to be realized by exchanging real assets for fiat money in the secondary market.

\subsection{Secondary Market}

The expected lifetime utility of an agent entering the secondary market with the portfolio accumulated in the primary market, $(m, a ; \kappa)$, is:

$$
\begin{aligned}
\mathbb{E} Z(m, a ; \kappa) & =(1-n)\left[\alpha V_{b}^{T}\left(m+p_{a} y_{b}, a-y_{b} ; \kappa_{b}\right)+(1-\alpha) V_{b}^{N}\left(m, a ; \kappa_{b}\right)\right] \\
& +n\left[\alpha V_{s}^{T}\left(m-p_{a} y_{s}, a+y_{s} ; \kappa_{s}\right)+(1-\alpha) V_{s}^{N}\left(m, a ; \kappa_{s}\right)\right],
\end{aligned}
$$

where $\alpha$ is the probability of finding a trading partner, determining the superscripts $\{T, N\}=$ \{trade, no trade\}, and $y \in[0, a]$ corresponds to the amount of assets traded at price $p_{a}$. In equilibrium, buyers will never purchase assets in the secondary market, since they are in need of fiat money to consume in the goods market. Sellers, on the contrary, have an incentive to purchase assets, since it allows them to alleviate the inflation tax on their current money holdings. ${ }^{8}$ At the same time, sellers have no incentive to sell assets, since they have no use for money and their role in the goods market is public information, which eliminates potential gains from trade through private information. Thus, given that reasoning, market clearing implies $y_{b}=y_{s}$. Before analyzing bilateral trades under private information, however, we first consider a complete-information benchmark scenario along the lines of Geromichalos and Herrenbrueck (2016).

\subsubsection{Bargaining under Complete Information}

Under complete information, both sides of the transaction are symmetrically informed about the future return of the asset, $\kappa$. In order to make the resulting allocations comparable to the ones in the subsequent signaling game, the terms of trade are restricted to buyers' take-

\footnotetext{
${ }^{8}$ This picks up the idea of Duffie et al. (2005), where the agents' motive for trading is driven through different valuations for a particular asset. Since liquidity needs vary in this environment, buyers and sellers have an incentive to trade assets for money on the over-the-counter market.
} 
it-or-leave-it offers, $\left(p_{a}, y\right)$, solving:

$$
\begin{aligned}
\left(p_{a}, y\right) \in \arg \max _{p_{a} y} & V_{b}^{T}\left(m+p_{a} y, a-y ; \kappa_{b}\right) \\
\text { s.t. } & y\left(\kappa_{b}-\phi p_{a}\right) \geq 0 \\
\text { s.t. } & a-y \geq 0
\end{aligned}
$$

where (17) corresponds to the seller's participation constraint and (18) is the buyer's feasibility constraint. Using the linearity of the centralized market value function, (5), and the fact that (17) is binding in equilibrium, the buyer's problem reduces to:

$$
\left(p_{a}, y\right) \in \arg \max _{p_{a} y} u\left[q^{T}\left(d^{T}\right)\right]-\beta \phi d^{T},
$$

subject to (17) and (18), with $d^{T}=m+p_{a} y, q^{T}=\beta \phi\left(m+p_{a} y\right)$, and $p_{a}=\kappa_{b} / \phi \cdot{ }^{9}$ From (14) we know that if $m \geq m^{*}$, a buyer can consume the socially-efficient quantity without trading in the secondary market, i.e., $q^{N}=q^{*}$. Since in this situation no surplus is generated, such transactions are ruled out. Instead, we focus on $m<m^{*}$ and thus $q^{N}=\beta \phi m<q^{*}$. Solving (19), the following first-order condition emerges:

$$
\beta \phi\left[u^{\prime}\left[\beta \phi\left(m+p_{a} y\right)\right]-1\right] \geq 0,
$$

which holds with equality if $p_{a} y \geq m^{*}-m$, i.e., if agents are unconstrained in their asset holdings. There are two cases to be considered, depending on whether the buyer's and seller's combined money holdings in a match allow for socially-efficient consumption: $2 m \geq m^{*}$ and $2 m<m^{*}$. For each of these two cases, two subcases regarding the buyer's' asset holdings exist: $a \geq \bar{a}\left(m ; \kappa_{b}\right)$ and $a<\bar{a}\left(m ; \kappa_{b}\right)$. These subcases determine whether the buyer holds enough assets to compensate the seller for his money holdings, whereas $\bar{a}\left(m ; \kappa_{b}\right)$ is defined as the buyer's critical level of asset holdings. All five regions are displayed in Figure 2 and summarized in Lemma B.

Definition B. An equilibrium of the complete-information bargaining game in the secondary market is a pair of strategies, $\left[p_{a}\left(m, a ; \kappa_{b}\right), y\left(m, a ; \kappa_{b}\right)\right]$, such that the terms of trade, $\left[p_{a}\left(m, a ; \kappa_{b}\right), y\left(m, a ; \kappa_{b}\right)\right]$, are a solution to the buyer's maximization problem, (19).

Lemma B. Under complete information, the equilibrium allocations solving (14) and (16) involve the following five regions:

\footnotetext{
${ }^{9}$ If agents were symmetrically uninformed, the secondary market price would simply correspond to the expected value, $p_{a}=R / \phi$.
} 


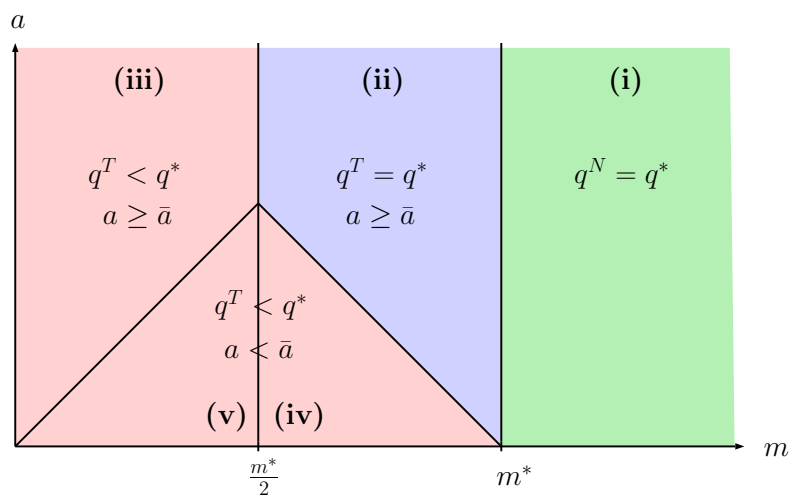

Figure 2: Equilibrium of the Benchmark Bargaining Game

(i) $m \geq m^{*}$

(ii) $2 m \geq m^{*}$ and $a \geq \bar{a}\left(m ; \kappa_{b}\right)$

(iii) $2 m<m^{*}$ and $a \geq \bar{a}\left(m ; \kappa_{b}\right)$ (iv) $2 m \geq m^{*}$ and $a<\bar{a}\left(m ; \kappa_{b}\right)$

(v) $2 m<m^{*}$ and $a<\bar{a}\left(m ; \kappa_{b}\right)$

and their corresponding equilibrium quantities:

$$
\begin{aligned}
q^{N} & =q^{*} \quad \text { in region (i) } \\
q^{T} & =\left\{\begin{array}{cc}
q^{*} & \text { in region (ii) } \\
2 q^{N}<q^{*} & \text { in region (iii) } \\
\beta \phi\left(m+p_{a} a\right)<q^{*} & \text { in region (iv) and (v) }
\end{array}\right. \\
y & =\left\{\begin{array}{cc}
0 & \text { in region (i) } \\
\bar{a}\left(m ; \kappa_{b}\right) & \text { in region (ii) and (iii) } \\
a & \text { in region (iv) and }(v),
\end{array}\right.
\end{aligned}
$$

with

$$
\bar{a}\left(m ; \kappa_{b}\right)=\left\{\begin{array}{cl}
\phi\left(m^{*}-m\right) / \kappa_{b} & \text { in region (ii) and (iv) } \\
\phi m / \kappa_{b} & \text { in region (iii) and (v). }
\end{array}\right.
$$

Proof in Appendix B.

Table 1 summarizes the comparative statics regarding $\bar{a}\left(m ; \kappa_{b}\right)$. The signs correspond to the partial derivatives of $\bar{a}\left(m ; \kappa_{b}\right)$ with respect to the variables in the top row:

\begin{tabular}{|c|c|c|c|}
\hline & $m$ & $\kappa_{b}$ & $\phi$ \\
\hline $\bar{a}$ & $-/+$ & - & + \\
\hline
\end{tabular}

Table 1: Comparative statics: Benchmark Bargaining Game 
The first derivative refers to the agent's money holdings, $m$, whereas two cases need to be distiguished. In general, the more money a buyer carries into the secondary market, the less he relies on the sale of assets and thus the lower the critical level of asset holdings, $\bar{a}\left(m ; \kappa_{b}\right)$. However, if the buyer's asset holdings are below the critical level, i.e., if $a<\bar{a}(m ; \kappa)$, an increase in the seller's money holdings raises the critical amount of assets the buyer needs to consume the socially efficient quantity. Hence, the more money the buyer can buy from the seller, the more assets he needs to carry into the secondary market to compensate the seller for his money holdings. The second derivative implies that the lower the return of the buyer's asset, $\kappa_{b}$, the more assets he needs to carry into the period to acquire the seller's money balances. Last but not least, the critical amount of assets the buyer needs to accumulate in the primary market increases with an increase in the value of money, $\phi$.

\subsubsection{Bargaining under Asymmetric Information}

Under asymmetric information, the bargaining game in the secondary market has the structure of a signaling game, i.e., the informed agent moves first and makes the offer. ${ }^{10}$ A strategy for the buyer is to specify an offer, $\left(y, p_{a}\right)$, whereas $y\left(m, a ; \kappa_{b}\right)$ and $p_{a}\left(m, a ; \kappa_{b}\right)$ are a function of the buyer's and seller's money holdings, the buyer's asset holdings, and the corresponding return $\kappa \in\left\{\kappa^{L}, \kappa^{H}\right\}$. Given the offer placed, the seller updates his beliefs and defines an acceptance rule, $\mathcal{A}_{s}$, that specifies the set of acceptable offers. Hence, the respective payoffs in the state $\kappa_{b}$ are:

$$
\begin{aligned}
Z_{b}\left(m, a ; \kappa_{b}\right) & =\alpha\left[V_{b}\left(m+p_{a} y, a-y ; \kappa_{b}\right) \mathbb{I}_{\mathcal{A}}+V_{b}\left(m, a ; \kappa_{b}\right)\left(1-\mathbb{I}_{\mathcal{A}}\right)\right] \\
& +(1-\alpha) V_{b}\left(m, a ; \kappa_{b}\right), \\
Z_{s}\left(m, a ; \kappa_{s}\right) & =\alpha\left[V_{s}\left(m-p_{a} y, a+y ; \kappa_{s}\right) \mathbb{I}_{\mathcal{A}}+V_{s}\left(m, a ; \kappa_{s}\right)\left(1-\mathbb{I}_{\mathcal{A}}\right)\right] \\
& +(1-\alpha) V_{s}\left(m, a ; \kappa_{s}\right) .
\end{aligned}
$$

where $\mathbb{I}_{\mathcal{A}} \in\{0,1\}$ is an indicator function equal to one iff $\left(y, p_{a}\right) \in \mathcal{A}_{s}$, and zero otherwise. Whether the offer satisfies the seller's acceptance rule, $\mathcal{A}_{s}$, depends on the seller's expectations about the terminal return of the buyer's asset. Let $\lambda=\operatorname{Prob}\left[\kappa_{b}=\kappa_{b}^{H} \mid\left(y, p_{a}\right)\right]$ be the seller's updated belief that the purchased asset is of high quality, i.e., $\kappa_{b}=\kappa_{b}^{H}$, conditional on the offer, $\left(y, p_{a}\right)$, made. The posterior expected value can therefore be formulated as:

$$
\mathbb{E}_{\lambda}=\lambda\left(y, p_{a}\right) \kappa_{b}^{H}+\left[1-\lambda\left(y, p_{a}\right)\right] \kappa_{b}^{L},
$$

\footnotetext{
${ }^{10}$ For the sake of this paper, I restrict the bargaining protocol to a signaling game, since screening games ex-ante alleviate the incentives to acquire assets. This is due to the fact that in a screening game, the total surplus of the high-type is extracted by the offering party.
} 
determining the seller's acceptance rule:

$$
\mathcal{A}_{s}(\lambda)=\left\{\left(y, p_{a}\right) \in \mathcal{F}: \mathbb{E}_{\lambda} V_{s}\left(m-p_{a} y, a+y ; \kappa_{s}\right) \geq 0\right\}
$$

Hence, for a given belief system, $\lambda\left(y, p_{a}\right)$, a seller accepts any offer yielding a non-negative surplus. Given the above acceptance rule, $\mathcal{A}_{s}(\lambda)$, the buyer holding an asset of quality $\kappa_{b}$ chooses an offer $\left(y, p_{a}\right)$ that maximizes his period utility. Since, without restriction, every allocation in this bargaining game can be a Perfect Bayesian Equilibrium, the equilibrium has to be refined in order to narrow the set of eligible equilibria. The refinement applied is the undefeated equilibrium established by Mailath et al. (1993), which endogenously selects among the least-inefficient separating equilibrium (Riley (1979)) and the most-efficient pooling equilibrium (Hellwig (1987)). To rule out Pareto inefficiencies, the choice between a pooling and a separating offer is endogenous and solely determined through maximization of the high-type's surplus, $V_{b}\left(m, a ; \kappa_{b}^{H}\right)$. In the following, separating and pooling equilibria are derived separately, starting with the Riley (1979) least-inefficient separating equilibrium.

\section{Separating Equilibrium}

When considering separating equilibria, the undefeated equilibrium relies on the Cho and Kreps (1987) Intuitive Criterion, whereas the proposed offer, $\left(y, p_{a}\right)$, fulfills the Intuitive Criterion if there exists no out-of-equilibrium offer, $\left(\tilde{y}, \tilde{p}_{a}\right)$, that satisfies:

$$
\begin{aligned}
V_{b}\left(m+p_{a}^{H} y^{H}, a-y^{H} ; \kappa_{b}^{H}\right) & <V_{b}\left(m+\tilde{p}_{a} \tilde{y}, a-\tilde{y} ; \kappa_{b}^{H}\right) \\
V_{b}\left(m+p_{a}^{L} y^{L}, a-y^{L} ; \kappa_{b}^{L}\right) & >V_{b}\left(m+\tilde{p}_{a} \tilde{y}, a-\tilde{y} ; \kappa_{b}^{L}\right) \\
V_{s}\left(m-\tilde{p}_{a} \tilde{y}, a+\tilde{y} ; \kappa_{s}\right) & \geq 0 .
\end{aligned}
$$

According to (27), the out-of-equilibrium offer, $\left(\tilde{y}, \tilde{p}_{a}\right)$, would make the high-type buyer strictly better off, if it were accepted. The low-type buyer, however, would be strictly worse off (see (28)), and according to (29), the offer would be accepted by the seller, since he believes that it comes from a high-type buyer. Such offers, $\left(\tilde{y}, \tilde{p}_{a}\right)$, are ruled out by the Intuitive Criterion.

In order to solve for the separating equilibrium, three steps need to be fulfilled. First, in Lemma C, it needs to be shown that under the Intuitive Criterion, no pooling equilibrium can exist. Second, among all Perfect Bayesian Equilibria, only the least-inefficient separating equilibrium survives the Intuitive Criterion (Lemma D). And third, a system of beliefs needs to be constructed that supports the least-inefficient separating equilibrium, hence defining 
the sellers' acceptance rule, $\mathcal{A}_{s}(\lambda)$.

Lemma C. In a separating equilibrium, there exists no pooling offer with $y>0$. Proof in Appendix $C$.

Low-Type Offer: In equilibrium, a low-type buyer can do no worse than to reveal his type and make the same offer he would make under complete information, since this offer is always acceptable to the seller, independent of his beliefs. At the same time, however, he cannot do any better, since otherwise his offer would have to be pooled with the one of a high-type buyer. Such out-of-equilibrium offers are ruled out by the Intuitive Criterion, as shown in Lemma C. Hence, the low-type buyer's problem is equivalent to the benchmark scenario in (19), with:

$$
\left(p_{a}^{L}, y^{L}\right) \in \arg \max _{p_{a} y} u\left[q^{T, L}\left(d^{T, L}\right)\right]-\beta \phi d^{T, L},
$$

subject to (17) and (18) with $\kappa_{b}=\kappa_{b}^{L}$, and the equilibrium quantities correspond to (21) in Lemma B with $p_{a}^{L}=\kappa_{b}^{L} / \phi$ and $d^{T, L}=m+p_{a}^{L} y^{L}$. The buyer's critical level of asset holdings is defined as $\bar{a}\left(m ; \kappa_{b}^{L}\right)=\phi\left(m^{*}-m\right) / \kappa_{b}^{L}$ if $2 m \geq m^{*}$, and $\bar{a}\left(m ; \kappa_{b}^{L}\right)=\phi m / \kappa_{b}^{L}$ if $2 m<m^{*}$. Comparative statics are analogue to the benchmark scenario and the resulting regions are visually displayed in Figure 2.

High-Type Offer: Among all incentive compatible offers, in equilibrium, the only offer a hightype buyer places is the one maximizing his surplus, while fulfilling the seller's participation constraint and the Intuitive Criterion. This offer is called the least-costly separating offer. For a reasonable system of beliefs, any other offer would give the high-type buyer an incentive to deviate, as shown in Lemma C. Thus, the high-type buyer's problem, placing an offer $\left(p_{a}^{H}, y^{H}\right)$, is:

$$
\begin{aligned}
&\left(p_{a}^{H}, y^{H}\right) \in \underset{p_{a} y}{\arg \max _{a}} u\left[q^{T, H}\left(d^{T, H}\right)\right]-\beta \phi d^{T, H} \\
& \text { s.t. } u\left[q\left(d^{T, L}\right)\right]+\beta\left(a-y^{L}\right) \kappa_{b}^{L} \geq u\left[q\left(d^{T, H}\right)\right]+\beta(a-y) \kappa_{b}^{L} \\
& \text { s.t. } y\left(\kappa_{b}^{H}-\phi p_{a}\right) \geq 0 \\
& \text { s.t. } a-y \geq 0,
\end{aligned}
$$

with $d^{T, H}=m+p_{a}^{H} y^{H}$, where the first constraint is an incentive compatibility constraint eliminating the low-type buyer's incentive to mimic the high-type's offer. The second constraint is the seller's participation constraint, and the third a feasibility constraint ruling out asset short-sales. Since we are considering take-it-or-leave-it offers, we know that the seller's participation constraint has to bind in equilibrium, and hence $p_{a}^{H}=\kappa_{b}^{H} / \phi$. 
Definition C. In a separating equilibrium, the belief system is determined by Bayes' rule as:

(i) $\lambda\left(\tilde{y}, \tilde{p}_{a}\right)=0 \forall\left(\tilde{y}, \tilde{p}_{a}\right) \notin \mathcal{O}$, and $V_{b}\left(m+\tilde{p}_{a} \tilde{y}, a-\tilde{y} ; \kappa_{b}^{L}\right)>V_{b}\left(m+p_{a}^{L} y^{L}, a-y^{L} ; \kappa_{b}^{L}\right)$

(ii) $\lambda\left(\tilde{y}, \tilde{p}_{a}\right)=1 \forall\left(\tilde{y}, \tilde{p}_{a}\right) \notin \mathcal{O}$, and $V_{b}\left(m+\tilde{p}_{a} \tilde{y}, a-\tilde{y} ; \kappa_{b}^{L}\right) \leq V_{b}\left(m+p_{a}^{L} y^{L}, a-y^{L} ; \kappa_{b}^{L}\right)$, where $\mathcal{O}$ is the set of equilibrium offers.

According to Definition C, any out-of-equilibrium offer that increases the payoff of the lowtype buyer compared to the complete-information offer in (30) is attributed to the low-type buyer, while any other out-of-equilibrium offer is attributed to the high-type, defining the acceptance rule:

$$
\begin{aligned}
\mathcal{A}_{s}(\lambda)=\left\{\left(p_{a}, y\right) \in \mathcal{F}:\right. & V_{b}\left(m+p_{a}^{H} y^{H}, a-y^{H} ; \kappa_{b}^{L}\right) \leq V_{b}\left(m+p_{a}^{L} y^{L}, a-y^{L} ; \kappa_{b}^{L}\right), \\
& \left.y^{H}\left(\kappa_{b}^{H}-\phi p_{a}^{H}\right) \geq 0\right\} .
\end{aligned}
$$

Definition D. An equilibrium of this bargaining game is a pair of strategies and a belief system, $\left\{\left[y\left(m, a ; \kappa_{b}\right), p_{a}\left(m, a ; \kappa_{b}\right)\right], \mathcal{A}_{s}(\lambda), \lambda\right\}$, such that:

(i) The terms of trade, $\left(y^{H}, p_{a}^{H}\right)$ and $\left(y^{L}, p_{a}^{L}\right)$, are a solution to the buyer's bargaining problem (30) and (31).

(ii) The seller's acceptance rule, $\mathcal{A}_{s}(\lambda)$, is given by (35).

(iii) The belief system, $\lambda\left(y, p_{a}\right)$, satisfies Bayes' rule and the Intuitive Criterion (27)-(29).

Lemma D. In a separating equilibrium, the goods market allocations of a low- and a hightype buyer, $\left(q^{T, L}, d^{T, L}\right)$ and $\left(q^{T, H}, d^{T, H}\right)$, solving (14), (30) and (31), correspond to:

$$
\begin{aligned}
q^{T, L} & =\beta \phi\left(m+p_{a}^{L} y^{L}\right) \leq q^{*} \\
d^{T, L} & =m+p_{a}^{L} y^{L} \\
q^{T, H} & =\beta \phi\left(m+p_{a}^{H} y^{H}\right)<q^{T, L} \\
d^{T, H} & =m+p_{a}^{H} y^{H},
\end{aligned}
$$

with $p_{a}^{L}=\kappa_{b}^{L} / \phi, p_{a}^{H}=\kappa_{b}^{H} / \phi, y^{L} \in[0, a]$, and $y^{H} \in\left[0, y^{L}\right)$. Proof in Appendix D. 


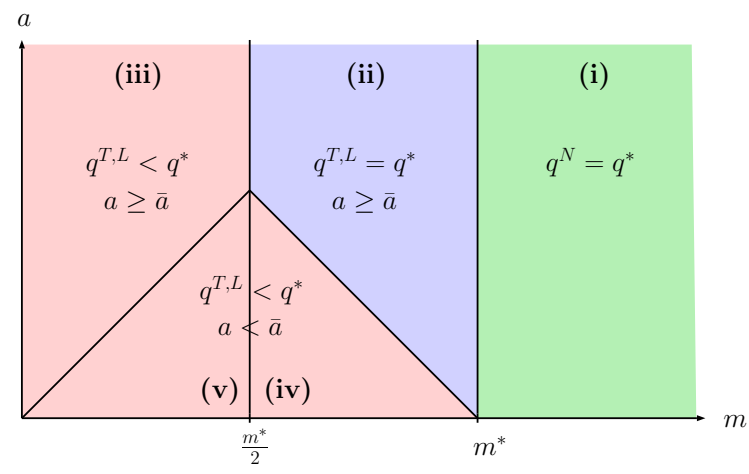

(a) Low-Type Buyer

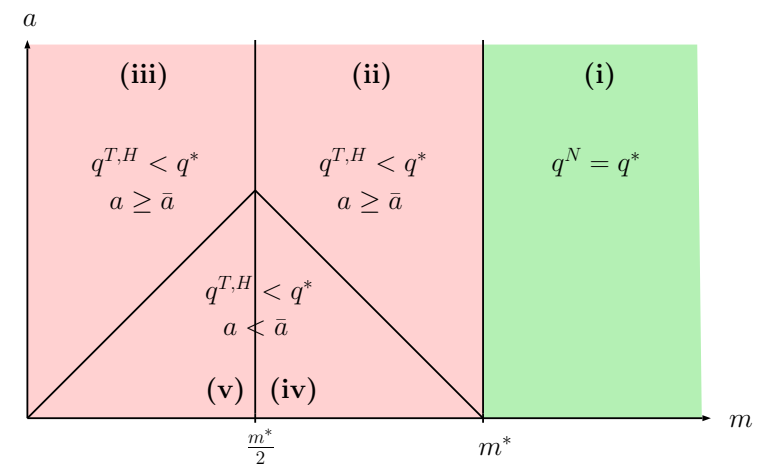

(b) High-Type Buyer

Figure 3: Separating Equilibrium

The equilibrium goods market allocations solving the low-type buyer's problem in (30), $\left(q^{T, L}, d^{T, L}\right)$, correspond to the ones in the benchmark scenario, described in Lemma B, with $\kappa_{b}=\kappa_{b}^{L}$. The resulting equilibrium regions are displayed in the left panel of Figure 3. Considering the problem of the high-type buyer, (31), from (32) it emerges that $q^{T, H}$ is uniquely determined and corresponds to the lowest $q^{T, H} \in\left[0, q^{T, L}\right)$ that fulfills (32). Since $q^{T, H}<q^{T, L}$, it follows immediately that $\beta \phi\left(m+p_{a}^{H} y^{H}\right)<\beta \phi\left(m+p_{a}^{L} y^{L}\right)$, and thus $y^{H}<y^{L}$, where $y^{L} \in[0, a]$ and $y^{H} \in\left[0, y^{L}\right)$. Hence, high-type buyers use the complete-information offer of the low-type buyer as a benchmark to separate themselves in order to secure better terms of trade in the secondary market, i.e., $p_{a}^{H}>p_{a}^{L}$. In doing so, separation takes place through asset retention, whereas a high-type buyer signalizes his high future returns, $\kappa_{b}^{H}$, through his willingness to sacrifice some consumption in the goods market by carrying parts of the asset into the subsequent primary market himself. Analog to Demarzo and Duffie (1999) and Guerrieri and Shimer (2014), the amount of assets retained is exactly at the threshold, such that the low-type buyer has no incentive to mimic the high-type buyer's offer. ${ }^{11}$ This result is an application of Gresham's Law, which states that the existence of lemons in the market crowds out good assets. Since the binding incentive compatibility constraint prevents the high-type buyer from consuming the socially-efficient quantity in the goods market, regions (ii) - (v) determined in Lemma B collapse into one, as displayed in the right panel of Figure 3. Lemmata E- G summarize the relevant comparative statics.

Lemma E. If $m<m^{*}$ and $a>0$, then $\partial \frac{y^{H}}{a} / \partial \kappa^{H}<0, \partial \frac{y^{H}}{a} / \partial \kappa^{L}>0$, and $\lim _{\kappa^{L} \rightarrow 0} y^{H} / a=0$. Proof in Appendix E.

As determined in Lemma E, the relative amount of high-quality assets sold, $y^{H} / a$, decreases

\footnotetext{
${ }^{11}$ Under complete information regarding the asset-quality, in equilibrium, the high-type buyer would consume a weakly higher quantity than the low-type buyer, $q^{T, H} \geq q^{T, L}$, and at the same time spend a lower fraction of his assets, $y^{H} \leq y^{L}$.
} 
with an increase in the distance between $\kappa^{H}$ and $\kappa^{L}$. Hence, the more severe the adverse selection in the economy, the more binding the incentive compatibility constraint, (32), and thus the lower the amount of assets sold by the high-type buyer, $y^{H} / a$. The limiting case, $\lim _{\kappa^{L} \rightarrow 0} y^{H} / a=0$, corresponds to the result established by Nosal and Wallace (2007) in a counterfeiting equilibrium and shows that the closer a low-value asset gets to being worthless, the lower the amount of high-value assets sold. For $\kappa^{L}=0$, separation breaks down.

Lemma F. If $m<m^{*}$ and $a>0$, then $\partial \beta y^{H} \kappa_{b}^{H} / \partial \beta \phi m<0$. Proof in Appendix F.

Lemma $\mathrm{F}$ addresses the substitutability of money and information-sensitive assets. By accumulating an additional unit of fiat money in the primary market, the high-type buyer can relax the incentive compatibility constraint, (32), and thus decrease his signaling costs by lowering the amount of assets retained. This relationship between $\beta \phi m$ and $\beta y^{H} \kappa_{b}^{H}$ characterizes the channel through which monetary policy is able to affect the trading volume on the secondary market.

Lemma G. If $\beta \phi\left(m+p_{a}^{L} y^{L}\right)<q^{*}$, then $\partial y^{H} / \partial a \in(0,1)$. However, if $\beta \phi\left(m+p_{a}^{L} y^{L}\right) \geq q^{*}$, then $\partial y^{H} / \partial a=0$. Proof in Appendix $G$.

In order to interpret Lemma $\mathrm{G}$, two cases need to be distinguished: $\beta \phi\left(m+p_{a}^{L} y^{L}\right)<q^{*}$ and $\beta \phi\left(m+p_{a}^{L} y^{L}\right) \geq q^{*}$. If the low-type buyer's liquidity needs are satiated, i.e., if $\beta \phi\left(m+p_{a}^{L} y^{L}\right) \geq q^{*}$, an additional unit of the asset does not relax the high-type buyer's incentive compatibility constraint, (51), and thus his willingness to sell another unit of the asset is zero, $\partial y^{H} / \partial a=0$. However, if $\beta \phi\left(m+p_{a}^{L} y^{L}\right)<q^{*}$, then an additional unit of the asset raises the low-type buyer's surplus. As a result, the high-type buyer's marginal willingness to sell is positive. However, since he can only sell a fraction of each additional asset without generating an incentive for the low-type buyer to mimic his offer, the high-type buyer's marginal willingness to sell is less than one, and hence $\partial y^{H} / \partial a \in(0,1)$.

\section{Pooling Equilibrium}

Having determined the least-costly separating equilibrium, we now consider a pooling equilibrium à la Hellwig (1987), in which the high-type buyer determines the terms of trade. This may allow him to circumvent the signaling costs associated to asset retention in a separating 
equilibrium. The high-type buyer's problem, placing a pooling offer $\left(\bar{y}, \bar{p}_{a}\right)$, is:

$$
\begin{aligned}
\left(\bar{p}_{a}, \bar{y}\right) & \in \underset{p_{a} y}{\arg \max _{a}} u\left[\bar{q}^{T}\left(\bar{d}^{T}\right)\right]-\beta \phi \bar{d}^{T} \\
\text { s.t. } & u\left[q\left(m+p_{a}^{L} y^{L}\right)\right]+\beta\left(a-y^{L}\right) \kappa_{b}^{L} \leq u\left[q\left(m+p_{a} y\right)\right]+\beta(a-y) \kappa_{b}^{L} \\
\text { s.t. } & y\left[R-\phi p_{a}\right] \geq 0 \\
\text { s.t. } & a-y \geq 0,
\end{aligned}
$$

with $\bar{d}^{T}=m+\bar{p}_{a} \bar{y}$. The first constraint corresponds to the low-type buyer's individual rationality constraint. The second constraint is the seller's acceptance rule, $\mathcal{A}_{s}(\lambda)$, and (41) the buyer's feasibility constraint. Since the seller is unaware of the buyer's asset quality, he only accepts the buyer's offer if gains from trade are positive in expectation, which is in line with the seller's acceptance rule in (26).

Definition E. An equilibrium of this bargaining game is a pair of strategies and a belief system, $\left\{\left[\bar{y}\left(m, a ; \kappa_{b}\right), \bar{p}_{a}\left(m, a ; \kappa_{b}\right)\right], \mathcal{A}_{s}(\lambda), \lambda\right\}$, such that:

(i) The terms of trade, $\left(\bar{y}, \bar{p}_{a}\right)$, are a solution to the high-type buyer's problem, (38).

(ii) The seller's acceptance rule, $\mathcal{A}_{s}(\lambda)$, is given by (26).

(iii) The belief system, $\lambda\left(\bar{y}, \bar{p}_{a}\right)$, satisfies Bayes' rule.

Lemma H. In a pooling equilibrium, the goods market allocations, $\left(\bar{q}^{T}, \bar{d}^{T}\right)$, solving (14) and (38), correspond to:

$$
\begin{aligned}
\bar{q}^{T} & =\beta \phi\left(m+\bar{p}_{a} \bar{y}\right)<q^{*}, \text { and } \\
\bar{d}^{T} & =m+\bar{p}_{a} \bar{y}
\end{aligned}
$$

with $\bar{p}_{a}=R / \phi, R=\pi^{L} \kappa^{L}+\pi^{H} \kappa^{H}$, and $\bar{y} \in[0, a]$. Proof in Appendix $H$.

A high-type buyer selling $\bar{y}$ units of his asset at a pooling price, $\bar{p}_{a}$, will never choose to sell as many assets to reach the socially-efficient quantity, $q^{*}$, and thus $\bar{q}<q^{*}$. This emerges from the first-order condition, $\partial / \partial \bar{p}_{a} \bar{y}$, yielding $u^{\prime}[\bar{q}]=\left(\beta R+\beta \kappa^{H}\right) / \beta R>1$. Due to the fact that in a pooling equilibrium, high-quality assets are sold below fundamental value, i.e., $\phi \bar{p}_{a}=R<\kappa^{H}$, the pooling price resembles a tax on consumption of the high-type buyers, and allows low-type buyers to free-ride on the high-type's high returns. In order to alleviate this tax burden, the high-type buyer lowers the quantity sold. Equivalent to the bargaining problem of a high-type buyer placing a separating offer, $\left(p_{a}^{H}, y^{H}\right)$, the equilibrium regions 
(ii) - (v) determined in Lemma B collapse into one, as displayed in the right panel of Figure 3.

Lemma I. If $m<m^{*}$ and $a>0$, then $\partial \frac{\bar{y}}{a} / \partial R<0$ and $\partial \bar{y} / \partial \beta \phi m<0$. Proof in Appendix I.

Analogue to the comparative statics in the separating equilibrium (Lemma E and F), Lemma I discusses the effect of the degree of adverse selection, $\frac{\kappa^{L}}{\kappa^{H}}$, and the buyer's real money holdings, $\phi m$, on the amount of assets sold in the most-efficient pooling equilibrium, $\bar{y}$. The first derivative with respect to $R$ shows that the higher the expected return of the buyer's asset, the lower the quantity sold in equilibrium, since given the higher expected value a high-type buyer is able to attain the same level of utility by selling a lower fraction of his high-value asset, thus alleviating the tax imposed through a pooling price. The second derivative captures the substitutability of the information-sensitive asset in a pooling equilibrium. The more money a buyer carries into the secondary market, the less assets he needs to sell to attain the desired level of consumption.

\subsection{Equilibrium of the Bargaining Game}

Having determined the equilibrium allocations corresponding to a separating and a pooling offer, we now endogenize the high-type buyer's choice between those two offers, depending on the degree of adverse selection prevailing in the market. In doing so, we invoke the undefeated equilibrium by Mailath et al. (1993). Definition F summarizes the full set of equilibria.

Definition F. The full set of Perfect Bayesian Equilibria maximizing the high-type buyer's payoff consists of a set of offers, $\left(y, p_{a}\right)$, defined by:

(i) (30) and (31) in a separating equilibrium, where $\left(y^{L}, p_{a}^{L}\right)$ corresponds to the low-type's offer, and $\left(y^{H}, p_{a}^{H}\right)$ to the offer of the high-type, and

(ii) (38) in a pooling equilibrium, where $\left(\bar{y}, \bar{p}_{a}\right)$ is the pooling offer.

All out-of-equilibrium offers, $\left(\tilde{y}, \tilde{p}_{a}\right)$, are associated to a low-type buyer.

Lemma J. The buyer's offer, $\left(y, p_{a}\right)$, and the resulting equilibrium in the bargaining game with private information is:

(i) $\left(y^{H}, p_{a}^{H}\right)$ in (31), and thus $\left(y^{L}, p_{a}^{L}\right)$ in $(30)$, if $V_{b}\left(m, a ; \kappa_{b}^{H}\right)>\bar{V}_{b}\left(m, a ; \kappa_{b}^{H}\right)$; and

(ii) $\left(\bar{y}, \bar{p}_{a}\right)$ in $(38)$ if $\bar{V}_{b}\left(m, a ; \kappa_{b}^{H}\right)>V_{b}\left(m, a ; \kappa_{b}^{H}\right)$, 
with $V_{b}\left(m, a ; \kappa_{b}^{H}\right)$ being the lifetime utility of a high-type buyer in a separating equilibrium, and $\bar{V}_{b}\left(m, a ; \kappa_{b}^{H}\right)$ in a pooling equilibrium. The seller's corresponding beliefs, $\lambda\left(y, p_{a}\right)$, supporting this equilibrium are such that:

(i) $\lambda=0$ for all offers that make the high-type buyer worse off and are preferred to $\left(\bar{y}, \bar{p}_{a}\right)$ by the low-type buyer;

(ii) $\lambda=1$ for all offers that make the low-type buyer strictly worse off than $\left(y^{L}, p_{a}^{L}\right)$; and (iii) $\lambda=\pi$ for all other offers. Proof in Appendix $J$.

Proposition A. For given asset returns, $0<\kappa^{L}<\kappa^{H}<\infty$, there exists a threshold value, $\tilde{\pi}^{H} \in(0,1)$, such that the equilibrium is pooling if $\tilde{\pi}^{H}<\pi^{H}$, and separating if $\tilde{\pi}^{H}>\pi^{H}$. Proof in Appendix K.

As determined in Proposition A, the high-type buyer's choice between placing a pooling or a separating offer depends on the distribution of assets, $\pi^{H}$ and $\pi^{L}$, in the economy. If the probability of encountering a high-quality asset is smaller than the threshold value, i.e., $\pi^{H}<\tilde{\pi}^{H}$, a separating offer, $\left(p_{a}^{H}, y^{H}\right)$, is the high type's optimal choice. However, if the probability of encountering a high-quality asset is particularly high, i.e., $\pi^{H}>\tilde{\pi}^{H}$, a hightype buyer is better off placing a pooling offer, $\left(\bar{p}_{a}, \bar{y}\right)$, since it allows him to circumvent the cost of separation. Thus, the notion of the undefeated equilibrium by Mailath et al. (1993) endogenously selects among pooling and separating offers, depending on the distribution of asset-qualities, $\pi^{H}$ and $\pi^{L}$, in the economy. This result is in line with the findings in $\mathrm{Li}$ and Rocheteau (2008), Bajaj (2016), and Madison (2017). In the limiting case with $\kappa^{L}=0$, no separating equilibrium is sustainable and a pooling contract, $\left(\bar{p}_{a}, \bar{y}\right)$, remains as the only feasible offer.

\section{General Equilibrium}

This section incorporates the solutions of the bargaining game into the general equilibrium structure of the model, and determines the agents' initial portfolio choice in the primary market. The timing of events implies that the agents' portfolio choice does not impart any private information about the assets' future return, since agents face their portfolio choice before being privately informed about the quality of their asset and their role in the goods market. The following market clearing conditions hold, with $N$ being the total number of 
agents in the economy:

$$
\begin{array}{r}
\int_{j \in N} a(j) d j=A \\
\int_{j \in N} m(j) d j=M .
\end{array}
$$

Using the linearity of the primary market value function, (5), and combining the goods market value function, (9), the secondary market value function, (15), and the primary market value function, (5), yields: ${ }^{12}$

$$
\begin{aligned}
(m, a) \in \arg \max _{m, a} & -\left(\phi_{t}-\beta \phi_{t+1}\right) m-\left(\varphi_{t}-\beta R\right) a \\
& +\quad(1-n) \sum_{\chi=L, H} \pi^{\chi}\left[\alpha S_{b}^{T}\left(m, a ; \kappa_{b}^{\chi}\right)+(1-\alpha) S_{b}^{N}\left(m, a ; \kappa_{b}^{\chi}\right)\right]
\end{aligned}
$$

where $S_{b}^{j}\left(m, a ; \kappa_{b}\right)=u\left[\beta \phi_{t+1} d^{j}\right]-\beta \phi_{t+1} d^{j}$ denotes the buyer's surplus with $j \in\{N, T\}$, and the terms of trade, $\left[q\left(m, a ; \kappa_{b}^{\chi}\right), d\left(m, a ; \kappa_{b}^{\chi}\right), p_{a}\left(m, a ; \kappa_{b}^{\chi}\right), y\left(m, a ; \kappa_{b}^{\chi}\right)\right]$, are a function of the agents' aggregate portfolio and the buyer's private signal, $\chi \in\{L, H\}$. They solve (11) and (12) in the goods market, (19) under complete information, (30) if $\kappa_{b}=\kappa_{b}^{L}$ and (31) if $\kappa_{b}=\kappa_{b}^{H}$ in a separating equilibrium, and (38) in a pooling equilibrium. The cost of purchasing and holding fiat money over one period is $-\left(\phi_{t}-\beta \phi_{t+1}\right) m$, while $-\left(\varphi_{t}-\beta R\right) a$ is the expected cost of buying and carrying a real asset across periods. Given (44), an agent chooses a portfolio, $(m, a)$, maximizing his expected surplus in the goods market, net of the cost of holding money and assets.

Definition G. An equilibrium is a list of portfolios, terms of trade in the secondary market, terms of trade in the goods market, and aggregate real balances, $\left\{[m(\cdot), a(\cdot)],\left[p_{a}(\cdot), y(\cdot)\right],[q(\cdot)\right.$, $d(\cdot)], M, A\}$, such that:

(i) $[m(\cdot), a(\cdot)]$ is a solution to (44) for all agents;

(ii) $\left[p_{a}(\cdot), y(\cdot)\right]$ is a solution to (19) under full information, (30) if $\kappa_{b}=\kappa_{b}^{L}$ and (31) if $\kappa_{b}=\kappa_{b}^{H}$ in a separating equilibrium, and (38) in a pooling equilibrium;

(iii) $[q(\cdot), d(\cdot)]$ is a solution to (11) and (12);

(iv) $M_{t+1}=(1+\tau) M_{t}$ is the law of motion of the money stock;

(v) $A_{t} \in \mathbb{R}_{+}$is the total supply of real assets in the economy; and

\footnotetext{
${ }^{12}$ The seller's portfolio choice in the centralized market does not matter, since through the given terms of trade and the timing of events, a seller is not able to extract any surplus. Hence, every agent chooses his portfolio in the hope that he encounters a consumption opportunity in the goods market.
} 
(vi) Market clearing conditions for $M$ and $A$, (43), hold.

The first-order conditions corresponding to (44) are:

$$
\begin{aligned}
& -\left(\phi_{t}-\beta \phi_{t+1}\right)+(1-n) \sum_{\chi=L, H} \pi^{\chi}\left[\alpha S_{b, m}^{T}\left(m, a ; \kappa_{b}^{\chi}\right)+(1-\alpha) S_{b, m}^{N}\left(m, a ; \kappa_{b}^{\chi}\right)\right] \leq 0 \\
& -\left(\varphi_{t}-\beta R\right)+(1-n) \sum_{\chi=L, H} \pi^{\chi}\left[\alpha S_{b, a}^{T}\left(m, a ; \kappa_{b}^{\chi}\right)\right] \leq 0
\end{aligned}
$$

with $S_{b, m}$ and $S_{b, a}$ being the partial derivatives of the buyer's surplus with respect to $m$ and $a$. If $\phi_{t}>\beta \phi_{t+1}$ or $\varphi_{t}>\beta R$, fiat money and real assets are costly hold and hence there is a unique solution to (44), satisfying (45) and (46). If $\phi_{t}=\beta \phi_{t+1}$ or $\varphi_{t}=\beta R$, they are costless to hold, and if $\phi_{t}<\beta \phi_{t+1}$ or $\varphi_{t}<\beta R$, money and assets yield a positive return and hence there is no solution, since all agents would store infinite amounts. Thus, in equilibrium we rule out the latter case.

\subsection{Complete Information}

Lemma K. Under complete information, there exists a unique solution to (44) with the equilibrium prices of money and assets in the primary market, $\left(\phi_{t}, \varphi_{t}\right)$, corresponding to:

$$
\begin{aligned}
\phi_{t} & =\beta \phi_{t+1}\left(1+\mathcal{L}_{m}^{c}\right) \\
\varphi_{t} & =\beta R\left(1+\mathcal{L}_{a}^{c}\right),
\end{aligned}
$$

with:

$$
\begin{aligned}
\mathcal{L}_{m}^{c} & =(1-n)\left[\alpha\left[\pi^{L}\left[u^{\prime}\left(q^{T, L}\right)-1\right]+\pi^{H}\left[u^{\prime}\left(q^{T, H}\right)-1\right]\right]+(1-\alpha)\left[u^{\prime}\left(q^{N}\right)-1\right]\right] \\
\mathcal{L}_{a}^{c} & =(1-n) \alpha R^{-1}\left[\pi^{L} \kappa^{L}\left[u^{\prime}\left(q^{T, L}\right)-1\right]+\pi^{H} \kappa^{H}\left[u^{\prime}\left(q^{T, H}\right)-1\right]\right]
\end{aligned}
$$

being the liquidity premia on money and assets under complete information, respectively, where $\left(q^{N}, q^{T}\right)$ solves (21) with $\kappa \in\left\{\kappa^{L}, \kappa^{H}\right\}$. Proof in Appendix L.

Proposition B. Under complete information, an agent's optimal portfolio choice in the primary market, $(m, a)$, solving (44), is characterized by five regions, as shown in Figure 4:

(i) $\gamma=\beta ; m \geq m^{*} ; q^{N}=q^{*} ; \mathcal{L}_{m}^{c}=0 ; \mathcal{L}_{a}^{c}=0$,

(ii) $\gamma \in(\beta, \tilde{\gamma}] ; 2 m \geq m^{*} ; a \geq \bar{a} ; q^{N}<q^{T}=q^{*} ; \mathcal{L}_{m}^{c} \geq 0 ; \mathcal{L}_{a}^{c}=0$

(iii) $\gamma \in(\tilde{\gamma}, \infty) ; 2 m<m^{*} ; a \geq \bar{a} ; q^{N}<q^{T}<q^{*} ; \mathcal{L}_{m}^{c}>0 ; \mathcal{L}_{a}^{c}>0$ 


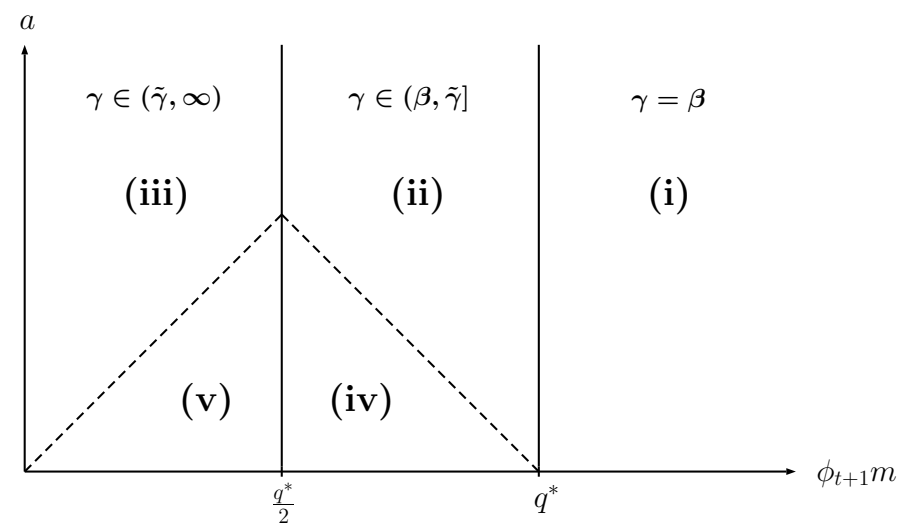

Figure 4: Portfolio Choice

$$
\begin{aligned}
& \text { (iv) } \gamma \in(\beta, \tilde{\gamma}] ; 2 m \geq m^{*} ; a<\bar{a} ; q^{N}<q^{T}<q^{*} ; \mathcal{L}_{m}^{c}>0 ; \mathcal{L}_{a}^{c}>0 \\
& \text { (v) } \gamma \in(\tilde{\gamma}, \infty) ; 2 m<m^{*} ; a<\bar{a} ; q^{N}<q^{T}<q^{*} ; \mathcal{L}_{m}^{c}>0 ; \mathcal{L}_{a}^{c}>0
\end{aligned}
$$

with $\gamma=\phi_{t} / \phi_{t+1}$, and $\gamma=\tilde{\gamma}$ fulfilling $2 m=m^{*}$. Proof in Appendix $M .^{13}$

Starting at the far right of Figure 4 in region (i), monetary policy is such that money is costless to hold, i.e., $\gamma=\beta$, and thus agents carry enough money into the period to acquire first-best consumption without reallocating assets in the secondary market, i.e., $m \geq m^{*}$ and $q^{N}=q^{*}$. Hence, agents have no demand for an additional unit of money or real assets, and thus both trade at the fundamental value in the primary market, i.e., $\mathcal{L}_{m}^{c}=0$ and $\mathcal{L}_{a}^{c}=0$. Since there are no gains from trade in the secondary market under this regime, $y=0$.

Moving towards the left, inflation increases to $\gamma \in(\beta, \tilde{\gamma}]$ and money becomes costly to hold. As a consequence, $m<m^{*}$, and thus $q^{N}<q^{*}$. However, the buyer's and seller's aggregate money holdings are still sufficient to consume the socially-efficient quantity, i.e., $2 m \geq m^{*}$, and thus consumption in the goods market depends on the global asset supply in the economy. If buyers are unconstrained in their asset holdings, i.e., if $a \geq \bar{a}\left(m ; \kappa_{b}\right)$ (see region (ii)), asset reallocation in the secondary market allows for socially-efficient consumption in the goods market, i.e., $q^{T}=q^{*}$. Since assets are in excess supply, $\mathcal{L}_{a}^{c}=0$, and $\varphi=\beta R$. Money, however, incorporates a positive liquidity premium, $\mathcal{L}_{m}^{c}>0$, due to the matching frictions in the secondary market, i.e., if $\alpha<1$. If, however, the buyer is constrained in his asset holdings (region (iv)), $a<\bar{a}\left(m ; \kappa_{b}\right)$, then $q^{T}<q^{*}$ for all $\gamma \in(\beta, \tilde{\gamma}]$. In this situation, fiat money incorporates a liquidity premium, $\mathcal{L}_{m}^{c}>0$, since an additional unit would allow the buyer to increase consumption in the goods market. Further, an additional unit of the asset would relax the buyer's liquidity constraint and thus, $\mathcal{L}_{a}^{c}>0$. We refer to this as an

\footnotetext{
${ }^{13}$ The four regions in Figure 4 correspond to the equilibrium regions determined in Section 2.4.
} 
indirect liquidity premium, since although real assets do not serve as a means of payment in the goods market, they can still indirectly relax the buyer's liquidity constraint through reallocation on the secondary market.

If the monetary authority further increases inflation to $\gamma \in(\tilde{\gamma}, \infty)$, money becomes very costly to hold and thus the agents' aggregate money holdings are too low to allow for sociallyefficient consumption, i.e., $2 m<m^{*}$. As a result, $q^{N}<q^{T}<q^{*}$ for both $a \gtrless \bar{a}\left(m ; \kappa_{b}\right)$, and thus $\mathcal{L}_{m}^{c}>0$ and $\mathcal{L}_{a}^{c}>0$ for $\gamma \in(\tilde{\gamma}, \infty)$. Hence, although agents in region (iii) are not constrained in their asset holdings, since $a \geq \bar{a}\left(m ; \kappa_{b}\right)$, the asset still trades above the fundamental value in the primary market, since real assets are in limited supply and allow agents to alleviate the high inflation tax on money. Comparative statics with respect to the matching friction are summarized in Lemma L.

Lemma L. If $m<m^{*}$, then $\partial \mathcal{L}_{m}^{c} / \partial \alpha<0, \partial \mathcal{L}_{a}^{c} / \partial \alpha>0$, and $\partial \mathcal{L}^{c} / \partial n<0$. Proof in $A p$ pendix $N$.

An increase in the probability of finding a trading partner in the secondary market, $\alpha$, decreases the liquidity premium on money, $\mathcal{L}_{m}^{c}$, and increases the liquidity premium on real assets, $\mathcal{L}_{a}^{c}$, since buyers enjoy a higher probability of reallocating their portfolio during the period. An increase in the probability of becoming a seller, $n$, however, decreases both liquidity premia and thus the ex-ante incentive to acquire money and real assets in the first place.

\subsection{Asymmetric Information}

Lemma M. Under asymmetric information, there exists a unique solution to (44) with the equilibrium prices of money and assets in the primary market, $\left(\phi_{t}, \varphi_{t}\right)$, corresponding to:

$$
\begin{aligned}
\phi_{t} & =\beta \phi_{t+1}\left(1+\mathcal{L}_{m}\right) \\
\varphi_{t} & =\beta R\left(1+\mathcal{L}_{a}\right),
\end{aligned}
$$


with:

$$
\begin{aligned}
\mathcal{L}_{m}^{S} & =(1-n)\left[\alpha\left[\pi^{L}\left[u^{\prime}\left(q^{T, L}\right)-1\right]+\pi^{H}\left[u^{\prime}\left(q^{T, H}\right)-1\right]\left[1+\frac{u^{\prime}\left(q^{T, L}\right)-1}{u^{\prime}\left(q^{T, H}\right)-1}\right]\right]+(1-\alpha)\left[u^{\prime}\left(q^{N}\right)-1\right]\right] \\
\mathcal{L}_{a}^{S} & =(1-n)\left[\alpha\left[\frac{\pi^{L} \kappa^{L}}{R}\left[u^{\prime}\left(q^{T, L}\right)-1\right]+\frac{\pi^{H} \kappa^{H}}{R}\left[u^{\prime}\left(q^{T, H}\right)-1\right]\left[\frac{u^{\prime}\left(q^{T, L}\right)-1}{\frac{\kappa^{H}}{\kappa^{L}} u^{\prime}\left(q^{T, H}\right)-1}\right]\right]\right] \\
\mathcal{L}_{m}^{P} & =(1-n)\left[\alpha\left[u^{\prime}(\bar{q})-1\right]+(1-\alpha)\left[u^{\prime}\left(q^{N}\right)-1\right]\right] \\
\mathcal{L}_{a}^{P} & =(1-n) \alpha\left[u^{\prime}(\bar{q})-1\right],
\end{aligned}
$$

where $\mathcal{L}=\mathcal{L}^{S}$ corresponds to the liquidity premium in a separating equilibrium, and $\mathcal{L}=\mathcal{L}^{P}$ in a pooling equilibrium. $\left(q^{N}, q^{T}\right)$ solve $(14)$, and $\left(p_{a}, y\right)$ solve (30) and (31) in a separating equilibrium, and (38) in a pooling equilibrium. Proof in Appendix $O$.

Lemma $\mathrm{M}$ determines the equilibrium primary market prices for fiat money and real assets, $\left(\phi_{t}, \varphi_{t}\right)$, under asymmetric information, where $\mathcal{L}_{m}^{S}, \mathcal{L}_{a}^{S}, \mathcal{L}_{m}^{P}$, and $\mathcal{L}_{a}^{P}$ are the liquidity premia of money and real assets in a separating and a pooling equilibrium, respectively. Consider first a separating equilibrium. The liquidity premium of money, $\mathcal{L}_{m}^{S}$, can be divided into three parts, whereas the first term on the right-hand side corresponds to the marginal surplus of money for a low-type buyer, the second to the high-type buyer, and the last to the marginal surplus of money if the buyer remains unmatched in the secondary market. Note that the high-type's surplus under complete information, $u\left(q^{T, H}\right)-1$, is multiplied by $1+\partial \beta y^{H} \kappa_{b}^{H} / \partial \beta \phi m<1$ to account for the asset retention performed in a separating equilibrium, as determined in Lemma $\mathrm{F}$. Thus the signaling costs associated to bargaining under private information in the secondary market reduce the primary market price of money in comparison to an environment without information frictions. Considering now the marginal surplus of another unit of the real asset in a separating equilibrium, $\mathcal{L}_{a}^{S}$, the first term on the right hand side denotes the marginal surplus of the low-type and corresponds to the liquidity value of a low-quality asset, $\kappa=\kappa^{L}$, under complete information. The complete-information outcome of the high-type, $\kappa^{H}\left[u\left(q^{T, H}\right)-1\right]$, captured at the beginning of the second term, however, is multiplied by $\partial y^{H} / \partial a \in(0,1)$, which corresponds to the high-type's marginal willingness to sell an additional unit of the asset on the secondary market under private information, as shown in Lemma G. Since a high-type buyer is suffering from a resalability constraint in a separating equilibrium, to fulfill the incentive compatibility constraint, (51), only a fraction of each additional unit of an asset can be sold on the secondary market. This has a direct effect on the primary market price of this particular asset. The intuition for the liquidity premia in a pooling equilibrium, $\mathcal{L}_{m}^{P}$ and $\mathcal{L}_{a}^{P}$, is analogue.

Proposition C. Under asymmetric information, an agent's optimal portfolio choice in the 
primary market, $(m, a)$, solving (44), is characterized by five regions, as shown in Figure 4:

$$
\begin{aligned}
& \text { (i) } \gamma=\beta ; m \geq m^{*} ; q^{N}=q^{*} ; \mathcal{L}_{m}=0 ; \mathcal{L}_{a}=0, \\
& \text { (ii) } \gamma \in(\beta, \tilde{\gamma}] ; 2 m \geq m^{*} ; a \geq \bar{a} ; q^{N}<q^{T, H}<\bar{q}<q^{T, L} \leq q^{*} ; \mathcal{L}_{m}>0 ; \mathcal{L}_{a}=0 \\
& \text { (iii) } \gamma \in(\tilde{\gamma}, \infty) ; 2 m<m^{*} ; a \geq \bar{a} ; q^{N}<q^{T}<q^{*} ; \mathcal{L}_{m}>0 ; \mathcal{L}_{a}>0 \\
& \text { (iv) } \gamma \in(\beta, \tilde{\gamma}] ; 2 m \geq m^{*} ; a<\bar{a} ; q^{N}<q^{T}<q^{*} ; \mathcal{L}_{m}>0 ; \mathcal{L}_{a}>0 \\
& \text { (v) } \gamma \in(\tilde{\gamma}, \infty) ; 2 m<m^{*} ; a<\bar{a} ; q^{N}<q^{T}<q^{*} ; \mathcal{L}_{m}>0 ; \mathcal{L}_{a}>0,
\end{aligned}
$$

with $\gamma=\phi_{t} / \phi_{t+1}$, and $\gamma=\tilde{\gamma}$ fulfilling $2 m=m^{*}$. Proof in Appendix P.

The equilibrium liquidity premia of money and real assets under asymmetric information can again be characterized by the five regions established in Section 2.4 and displayed in Figure 4. In this paragraph, however, I will only focus on the difference emerging from the introduction of information frictions in the economy. To do this, we restrict attention to region (ii) with $\gamma \in(\beta, \tilde{\gamma}]$ and $a \geq \bar{a}\left(m ; \kappa_{b}\right)$. Consider first a separating equilibrium. If $a \geq \bar{a}\left(m ; \kappa_{b}^{L}\right)$, a low-type buyer can consume the socially-efficient quantity, $q^{T, L}=q^{*}$, if matched in the secondary market. High-type buyers, however, consume less, i.e., $q^{T, H}<q^{T, L}=q^{*}$, due to their limited ability to sell, imposed through the incentive compatibility constraint, (51). As a result, real assets do not incorporate a liquidity premium, i.e., $\mathcal{L}_{a}^{S}=0$, since the low-type buyer does not want to purchase an additional unit of the search good in the goods market, and the high-type is facing a binding resalability constraint. Money, however, incorporates a strictly positive liquidity premium, $\mathcal{L}_{m}^{S}>0$ for all $\alpha \in(0,1]$, since it allows the high-type buyer to increase consumption without creating an incentive for the low-type buyer to mimic his offer, as shown in Lemma F. Being aware of this result, the same holds for the pooling equilibrium, since an additional unit of fiat money allows the high-type buyer to decrease the tax burden stemming from the pooling price (see Lemma I). As a consequence, if $\gamma \in(\beta, \tilde{\gamma}]$ and $a \geq \bar{a}\left(m ; \kappa_{b}\right)$, then $\mathcal{L}_{a}^{P}=0$ and $\mathcal{L}_{m}^{P}>0$ for all $\alpha \in(0,1]$. Taking this into consideration, regions (iii), (iv), and (v) behave accordingly. Proposition D summarizes.

Proposition D. Under asymmetric information, for $m<m^{*}$, it holds that $\mathcal{L}_{m}>\mathcal{L}_{a} \geq 0$ for all $\alpha \in(0,1] . \mathcal{L}_{m}>0$ if and only if $m<m^{*} ; \mathcal{L}_{a}^{P}>0$ if and only if $\beta(\phi m+a R)<q^{*}$; and $\mathcal{L}_{a}^{S}>0$ if and only if $\beta\left(\phi m+a \kappa_{b}^{L}\right)<q^{*}$. Proof in Appendix $Q$.

Proposition D addresses the liquidity structure of fiat money and real assets under private information. The results show that, for $\gamma>\beta$, there emerges a positive rate-of-return differential between fiat money and real assets with $\mathcal{L}_{m}>\mathcal{L}_{a} \geq 0$ for all values of $\alpha \in[0,1]$, i.e., 
even if the secondary market is frictionless $(\alpha=1)$. Assets start to incur a positive liquidity premium once a buyer is constrained in his asset holdings. Thus, $\mathcal{L}_{a}^{S}>0$ if $\beta\left(\phi m+a \kappa_{b}^{L}\right)<q^{*}$, and $\mathcal{L}_{a}^{P}>0$ if $\beta(\phi m+a R)<q^{*}$. This is the main difference to the benchmark scenario under complete-information, where in region i.a., the value of money is exclusively determined through the prevailing inflation rate, $\gamma$, and the matching friction, $\alpha$, with $\mathcal{L}_{m}=0$ and $\mathcal{L}_{a}=0$ for $\alpha=1$.

Proposition E. For all $\alpha \in(0,1]$, if $m<m^{*}$, then $\partial \mathcal{L}_{m} / \partial \beta \phi m<0$, and $\partial\left(\mathcal{L}_{m}-\right.$ $\left.\mathcal{L}_{a}\right) / \partial \beta \phi m<0$. If $\beta\left(\phi m+a \kappa_{b}^{L}\right)<q^{*}$, then $\partial \mathcal{L}_{a}^{S} / \partial \beta \phi m<0$, and if $\beta(\phi m+a R)<q^{*}$, then $\partial \mathcal{L}_{a}^{P} / \partial \beta \phi m<0$. Proof in Appendix $R$.

Proposition E shows that for $m<m^{*}$, the liquidity premium on money declines with an increase in the money balances, $\partial \mathcal{L}_{m} / \partial \beta \phi m<0$, and so does the liquidity differential, $\partial\left(\mathcal{L}_{m}-\mathcal{L}_{a}\right) / \partial \beta \phi m<0$. For $\beta\left(\phi m+a \kappa_{b}^{L}\right)<q^{*}$ in a separating equilibrium, and $\beta(\phi m+a R)<q^{*}$ in a pooling equilibrium, the liquidity premium on assets decreases with an increase in the amount of fiat money accumulated in the primary market, i.e., $\partial \mathcal{L}_{a} / \partial \beta \phi m<0$. Intuitively, if due to a change in monetary policy a buyer holds a higher amount of real money balances, $\beta \phi m$, he can consume more goods in the goods market, independent of the information friction prevailing in the economy. Thus, by substituting one unit of the information-sensitive asset for an additional unit of money, buyers can relax their incentive compatibility constraint, reducing the marginal benefit of holding an additional unit of either money or assets. As a result, the rate-of-return differential narrows. This is in line with the results in Rocheteau (2011).

\section{Policy Implications}

The results of the model have shown that private information regarding the quality of a traded real asset reduces asset liquidity on the secondary market due to binding incentive compatibility constraints. This has a direct effect on consumption in the goods market. As a consequence, a positive rate-of-return differential between money and real assets emerges, where the price of money on the primary market inherits a higher liquidity premium, since an additional unit of fiat money would relax a high-type buyer's liquidity constraint, and thus increase consumption, as shown in Proposition D and Proposition E. Given that reasoning, the welfare benefits of a policy intervention along the lines of Tirole (2012), replacing information-sensitive assets with fiat money or real bonds, are apparent. While fiscal policy would involve the fiscal authority replacing assets for government bonds, monetary policy 
requires the central bank to exchange assets for fiat money, as done in the asset-purchase program implemented by the Federal Reserve Bank in the aftermath of the global financial crisis.

\section{Conclusion}

The goal of this paper is to analyze the relationship between monetary policy, asset prices, liquidity, and optimal portfolio choice in an environment with private information regarding the quality of assets traded on secondary over-the-counter markets. Using an infinite-time dynamic general equilibrium model involving search and bilateral bargaining, the results show that information frictions reduce the liquidity of information-sensitive assets, resulting in a rate-of-return differential between fiat money and real assets. As a consequence, the incentive to invest into such information-sensitive assets on the primary market decreases, while the demand for fiat money increases, as observed in the aftermath of the global financial crisis. Next to that, the results show that a policy replacing information-sensitive assets with information-insensitive government bonds or fiat money can be welfare improving. 


\section{References}

Acharya, V. V. and Merrouche, O. (2012), 'Precautionary hoarding of liquidity and interbank markets: Evidence from the subprime crisis', Review of Finance 17(1), 107-160.

Acharya, V. V., Shin, H. S. and Yorulmazer, T. (2011), 'Crisis resolution and bank liquidity', Review of Financial Studies 24(6), 2166-2205.

Acharya, V. V. and Skeie, D. (2011), 'A model of liquidity hoarding and term premia in inter-bank markets', Journal of Monetary Economics 58(5), 436-447.

Akerlof, G. A. (1970), 'The market for lemons: Quality uncertainty and the market mechanism', The Quarterly Journal of Economics 84(3), 488-500.

Ashcraft, A., McAndrews, J. and Skeie, D. (2011), 'Precautionary reserves and the interbank market', Journal of Money, Credit and Banking 43(7), 311-348.

Bajaj, A. (2016), 'Adverse selection and liquidity in asset markets', Working Paper.

Berentsen, A., Camera, G. and Waller, C. (2007), 'Money, credit and banking', Journal of Economic Theory 135(1), 171-195.

Berentsen, A., Marchesiani, A. and Waller, C. J. (2014), 'Floor systems for implementing monetary policy: Some unpleasant fiscal arithmetic', Review of Economic Dynamics $\mathbf{1 7}(3), 523-542$.

Berentsen, A., McBride, M. and Rocheteau, G. (2017), 'Limelight on dark markets: Theory and experimental evidence on liquidity and information', Journal of Economic Dynamics and Control 75, 70-90.

Berentsen, A. and Monnet, C. (2008), 'Monetary policy in a channel system', Journal of Monetary Economics 55(6), 1067-1080.

Berentsen, A. and Müller, B. (2015), 'A tale of fire-sales and liquidity hoarding', Working Paper.

Bolton, P., Santos, T. and Scheinkman, J. A. (2011), 'Outside and inside liquidity', The Quarterly Journal of Economics 126(1), 259-321.

Burdett, K. and Judd, K. L. (1983), 'Equilibrium price dispersion', Econometrica 51(4), 955969.

Caballero, R. J. and Krishnamurthy, A. (2008), 'Collective risk management in a flight to quality episode', The Journal of Finance 63(5), 2195-2230. 
Chang, B. (2017), 'Adverse selection and liquidity distortion', Review of Economic Studies forthcoming pp. 1-44.

Chiu, J. and Koeppl, T. V. (2016), 'Trading dynamics with adverse selection and search: Market freeze, intervention and recovery', The Review of Economic Studies 83(3), 9691000.

Cho, I.-K. and Kreps, D. M. (1987), 'Signaling games and stable equilibria', The Quarterly Journal of Economics 102(2), 179-221.

Demarzo, P. and Duffie, D. (1999), 'A liquidity-based model of security design', Econometrica 67(1), 65-99.

Diamond, D. W. and Rajan, R. G. (2011), 'Fear of fire sales, illiquidity seeking, and credit freezes', The Quarterly Journal of Economics 126(2), 557-591.

Duffie, D., Garleanu, N. and Pedersen, L. H. (2005), 'Over-the-counter markets', Econometrica $73(6), 1815-1847$.

Eisfeldt, A. L. (2004), 'Endogenous liquidity in asset markets', The Journal of Finance $\mathbf{5 9}(1), 1-30$.

Gale, D. and Yorulmazer, T. (2013), 'Liquidity hoarding', Theoretical Economics 8(2), 291324.

Geromichalos, A. and Herrenbrueck, L. (2016), 'Monetary policy, asset prices, and liquidity in over-the-counter markets', Journal of Money, Credit and Banking 48(1), 35-79.

Geromichalos, A., Licari, J. M. and Suárez-Lledó, J. (2007), 'Monetary policy and asset prices', Review of Economic Dynamics 10(4), 761-779.

Gorton, G. and Metrick, A. (2012), 'Securitized banking and the run on repo', Journal of Financial Economics 104(3), 425-451.

Gorton, G. and Ordoñez, G. (2014), 'Collateral crises', American Economic Review 104(2), 343-378.

Guerrieri, V. and Shimer, R. (2014), 'Dynamic adverse selection: A theory of illiquidity, fire sales, and flight to quality', American Economic Review 104(7), 1875-1908.

Guerrieri, V., Shimer, R. and Wright, R. (2010), 'Adverse selection in competitive search equilibrium', Econometrica 78(6), 1823-1862.

Heider, F., Hoerova, M. and Holthausen, C. (2015), 'Liquidity hoarding and interbank market rates: The role of counterparty risk', Journal of Financial Economics 118(2), 336-354. 
Hellwig, M. (1987), 'Some recent developments in the theory of competition in markets with adverse selection', European Economic Review 31, 319-325.

Hicks, J. R. (1935), 'A suggestion for simplifying the theory of money', Economica 2(5), 1-19.

Inada, K.-I. (1963), 'On a two-sector model of economic growth: Comments and a generalization', The Review of Economic Studies 30(2), 119-127.

Jacquet, N. L. and Tan, S. (2012), 'Money and asset prices with uninsurable risks', Journal of Monetary Economics 59(8), 784-797.

Kocherlakota, N. R. (1998), 'Money is memory', Journal of Economic Theory 81(2), 232-251.

Lagos, R. (2010), 'Asset prices and liquidity in an exchange economy', Journal of Monetary Economics 57(8), 913-930.

Lagos, R. (2011), 'Asset prices, liquidity, and monetary policy in an exchange economy', Journal of Money, Credit and Banking 43(7), 521-552.

Lagos, R. and Rocheteau, G. (2008), 'Money and capital as competing media of exchange', Journal of Economic Theory 142(1), 247-258.

Lagos, R. and Rocheteau, G. (2009), 'Liquidity in asset markets with search frictions', Econometrica $77(2)$, 403-426.

Lagos, R., Rocheteau, G. and Weill, P.-O. (2011), 'Crises and liquidity in over-the-counter markets', Journal of Economic Theory 146(6), 2169-2205.

Lagos, R. and Wright, R. (2005), 'A unified framework for monetary theory and policy analysis', Journal of Political Economy 113(3), 463-484.

Lagos, R. and Zhang, S. (2015), 'Monetary exchange in over-the-counter markets: A theory of speculative bubbles, the fed model, and self-fulfilling liquidity crises', Working Paper .

Lauermann, S. and Wolinsky, A. (2016), 'Search with adverse selection', Econometrica 84(1), 243-315.

Lester, B., Postlewaite, A. and Wright, R. (2012), 'Information, liquidity, asset prices, and monetary policy', The Review of Economic Studies 79(3), 1209-1238.

Li, Y. and Rocheteau, G. (2008), 'Undefeated counterfeiting equilibria', Working Paper .

Lucas, R. E. (1978), 'Asset prices in an exchange economy', Econometrica 46(6), 1429-1445.

Madison, F. (2017), 'Asymmetric information in frictional markets for liquidity: Collateralized credit vs asset sale', Working Paper. 
Mailath, G. J., Okuno-Fujiwara, M. and Postlewaite, A. (1993), 'Belief-based refinements in signaling games', Journal of Economic Theory 60(2), 241-276.

Malherbe, F. (2014), 'Self-fulfilling liquidity dry-ups', The Journal of Finance 69(2), 947970.

Mattesini, F. and Nosal, E. (2016), 'Liquidity and asset prices in a monetary model with OTC asset markets', Journal of Economic Theory 164, 187-217.

Morris, S. and Shin, H. S. (2012), 'Contagious adverse selection', American Economic Journal: Macroeconomics 3(4), 1-21.

Nosal, E. and Wallace, N. (2007), 'A model of (the threat of) counterfeiting', Journal of Monetary Economics 54(4), 994-1001.

Plantin, G. (2009), 'Learning by holding and liquidity', The Review of Economic Studies 76(1), 395-412.

Riley, J. G. (1979), 'Informational equilibrium', Econometrica 47(2), 331-359.

Rocheteau, G. (2011), 'Payments and liquidity under adverse selection', Journal of Monetary Economics 58(3), 191-205.

Rothschild, M. and Stiglitz, J. (1976), 'Equilibrium in competitive markets: An essay on the economics of imperfect information', The Quarterly Journal of Economics 90(4), 629-649.

Shi, S. (1995), 'Money and prices: A model of search and bargaining', Journal of Economic Theory 67, 467-496.

Shi, S. (2006), 'Viewpoint: A microfoundation of monetary economics', Canadian Journal of Economics 39(3), 643-688.

Tirole, J. (2012), 'Overcoming adverse selection: How public intervention can restore market functioning', American Economic Review 102(1), 29-59.

Tobin, J. (1965), 'Money and economic growth', Econometrica 33(4), 671-684.

Trejos, A. and Wright, R. (1995), 'Search, bargaining, money, and prices', Journal of Political Economy 103(1), 118-141.

Trejos, A. and Wright, R. (2016), 'Search-based models of money and finance: An integrated approach', Journal of Economic Theory 164, 10-31.

Wallace, N. (2001), 'Whither monetary economics?', International Economic Review 42(4), 847-869. 
Weill, P.-O. (2007), 'Leaning against the wind', Review of Economic Studies 74(4), 13291354.

Williams, B. (2016), 'Search, liquidity, and retention: Signaling multidimensional private information', Working Paper pp. 1-40.

Wilson, C. (1980), 'The nature of equilibrium in markets with adverse selection', The Bell Journal of Economics 11(1), 108-130. 


\section{Appendix}

\section{A. Proof of Lemma A}

To derive the equilibrium allocations in Lemma A, first solve the seller's bargaining problem in (11). Then solve the buyer's bargaining problem in (12) using the designated Lagrange multiplier, and combine the resulting first-order condition with the one of the seller's problem to get (13).

\section{B. Proof of Lemma B}

In order to derive the results in Lemma B, I proceed case by case.

Region (ii) and (iv): $2 m \geq m^{*}$, i.e., there is enough money in the environment to afford $q^{T}=q^{*}$. Thus, the equilibrium allocations depend on the buyer's asset holdings, $a$. If $a>\bar{a}\left(m ; \kappa_{b}\right)$, then the buyer has enough assets to compensate the seller, and thus $q^{T}=q^{*}$ and $p_{a} y=m^{*}-m$. Plugging the latter into the seller's participation constraint, replacing $y$ with $\bar{a}\left(m ; \kappa_{b}\right)$, and solving after $\bar{a}\left(m ; \kappa_{b}\right)$, yields:

$$
\bar{a}\left(m ; \kappa_{b}\right)=\frac{\phi\left(m^{*}-m\right)}{\kappa_{b}}
$$

and denotes the critical level of asset holdings in the case where $2 m \geq m^{*}$. Two subcases need to be considered: If $a \geq \bar{a}\left(m ; \kappa_{b}\right)$, then $y=\bar{a}\left(m ; \kappa_{b}\right)$, and the buyer sells exactly the amount of assets needed to acquire $q^{T}=q^{*}$. If $a<\bar{a}\left(m ; \kappa_{b}\right)$, however, the buyer is constrained in his asset holdings and thus sells all his assets to maximize utility of consumption, i.e., $y=a$. The resulting equilibrium quantity equals $q^{T}=\beta \phi\left(m+p_{a} a\right)<q^{*}$.

Region (iii) and $(v)$ : $2 m<m^{*}$, i.e., in aggregate, agents are constrained in their money holdings. If $a>\bar{a}\left(m ; \kappa_{b}\right)$, then $p_{a} y=m$, and the buyer purchases all of the seller's money holdings, yielding $q^{T}=2 q^{N}<q^{*}$. Again, plugging $p_{a} y=m$ into the seller's participation constraint and replacing $y$ with $\bar{a}\left(m ; \kappa_{b}\right)$, we get:

$$
\bar{a}\left(m ; \kappa_{b}\right)=\frac{\phi m}{\kappa_{b}},
$$

which denotes the critical level of asset holdings in the case where $2 m<m^{*}$. If $a \geq \bar{a}\left(m ; \kappa_{b}\right)$,

then $y=\bar{a}\left(m ; \kappa_{b}\right)$ and $p_{a} y=m$. If $a<\bar{a}\left(m ; \kappa_{b}\right)$, however, then $y=a$ and thus $q^{T}=$ $\beta \phi\left(m+p_{a} a\right)<q^{*}$. 


\section{Proof of Lemma C}

Assume that there exists a pooling equilibrium with $y>0$, in which all assets are traded at the same price, $p_{a}$. The ask price a high-type buyer would demand for one additional unit

of his asset, $p_{a}^{H}$, is higher than the ask price of the low-type buyer, $p_{a}^{L}$. Hence, the high-type buyer can signal his type by offering a lower amount of assets, reducing his consumption in the goods market. However, due to the concavity of $u(q)$, this would increase his payoff, while the low-type buyer would be worse of, since his goods market consumption would be lower than in the proposed pooling equilibrium. Given that reasoning, the seller would attribute such a separating offer to a high-type buyer and accept it, since he was willing to accept the pooling offer in the first place. Hence, under the Cho and Kreps (1987) Intuitive Criterion, the equilibrium needs to be separating.

\section{Proof of Lemma D}

To derive the equilibrium allocations in Lemma D, solve the bargaining problem of the low- and the high-type buyer, (30) and (31) respectively, and combine the results with the equilibrium allocations determined in the goods market, (14). From the goods market problem we know that if $m<m^{*}$, then $q^{T}=\beta \phi\left(m+p_{a} y\right)$ if trade in the secondary market takes place. Rewriting the buyers' incentive compatibility constraint, (32), and plugging in $q^{T}$, then $\left(q^{T, H}, y^{H}\right) \in\left[0, q^{T, L}\right] \times[0, a]$ is the unique solution to:

$$
\begin{aligned}
\beta y^{H} \kappa_{b}^{H} & =q^{T, H}-\beta \phi m, \text { and } \\
u\left(q^{T, L}\right)-q^{T, L} & =u\left(q^{T, H}\right)-q^{T, H}+\left(1-\frac{\kappa_{b}^{L}}{\kappa_{b}^{H}}\right)\left(q^{T, H}-\beta \phi m\right) .
\end{aligned}
$$

\section{E. Proof of Lemma E}

From Lemma D, if $m<m^{*}$ and $a>0$, then $q^{T, H}$ is the unique solution in $\left[0, q^{T, L}\right]$ to (51). 
Differentiate (51):

$$
\begin{aligned}
& \frac{\partial q^{T, H}}{\partial \kappa_{b}^{H}}=-\frac{\frac{\kappa_{b}^{L}}{\kappa_{b}^{H}} \beta y^{H}}{u^{\prime}\left(q^{T, H}\right)-\frac{\kappa_{b}^{L}}{\kappa_{b}^{H}}}<0 \\
& \frac{\partial q^{T, H}}{\partial \kappa_{b}^{L}}=\frac{\left[u^{\prime}\left(q^{T, L}\right)-1\right] \beta a+\beta y^{H}}{u^{\prime}\left(q^{T, H}\right)-\frac{\kappa_{b}^{L}}{\kappa_{b}^{H}}}>0,
\end{aligned}
$$

where $q^{T, L}=\min \left[1, \phi \beta\left(m+p_{a}^{L} y^{L}\right)\right]$ and $y^{H}>0$. Using the first equation in (51), differentiating, and combining with $\frac{\partial q^{T, H}}{\partial \kappa_{b}^{H}}$ and $\frac{\partial q^{T, H}}{\partial \kappa_{b}^{L}}$, yields:

$$
\begin{aligned}
& \frac{\partial y^{H}}{\partial \kappa_{b}^{L}}=\frac{1}{\kappa_{b}^{H}} \frac{\partial q^{T, H}}{\partial \kappa_{b}^{L}}>0 \\
& \frac{\partial y^{H}}{\partial \kappa_{b}^{H}}=-\frac{u^{\prime}\left(q^{T, H}\right) \beta y^{H}}{\kappa_{b}^{H} u^{\prime}\left(q^{T, H}\right)-\kappa_{b}^{L}}<0 .
\end{aligned}
$$

The fact that $y^{H} / a=0$ if $\kappa_{b}^{L}=0$ is straighforward from (51).

\section{F. Proof of Lemma F}

Using the rewritten incentive compatibility constraint, (51), with $q^{T, L}=\beta \phi\left(m+p_{a}^{L} y^{L}\right)$ and $q^{T, H}=\beta \phi\left(m+p_{a}^{H} y^{H}\right)$, solving for $\beta y^{H} \kappa^{H}$, and taking the derivative with respect to $\beta \phi m$ yields:

$$
\frac{\partial \beta y^{H} \kappa_{b}^{H}}{\partial \beta \phi m}: \frac{u^{\prime}\left(q^{T, L}\right)-1}{u^{\prime}\left(q^{T, H}\right)-1}<0,
$$

for $m<m^{*}$, since $q^{T, H}<q^{T, L}$ in a separating equilibrium.

\section{G. Proof of Lemma G}

The derivation of Lemma $G$ follows a similar logic than the one of Lemma F. Using (51) with $q^{T, L}=\beta \phi\left(m+p_{a}^{L} y^{L}\right)$ and $q^{T, H}=\beta \phi\left(m+p_{a}^{H} y^{H}\right)$, and taking the derivative of $y^{H}$ with respect to $a$, yields:

$$
\frac{\partial y^{H}}{\partial a}: \frac{u^{\prime}\left(q^{T, L}\right)-1}{\frac{\kappa_{b}^{H}}{\kappa_{b}^{L}} u^{\prime}\left(q^{T, H}\right)-1} \in(0,1),
$$

for $\beta \phi\left(m+p_{a}^{L} y^{L}\right)<q^{*}$, since $u^{\prime}\left(q^{T, L}\right)<u^{\prime}\left(q^{T, H}\right)$ and $\kappa^{L}<\kappa^{H}$. For $\beta \phi\left(m+p_{a}^{L} y^{L}\right) \geq q^{*}$, however, $\frac{\partial y^{H}}{\partial a}=0$. 


\section{H. Proof of Lemma $\mathrm{H}$}

To derive the equilibrium allocations in Lemma $\mathrm{H}$, solve the bargaining problem of the high-type buyer placing a pooling offer, (38), and combine the results with the equilibrium allocations determined in the goods market, (14).

\section{Proof of Lemma I}

Take the equilibrium consumption, $\bar{q}^{T}=\beta(\phi m+\bar{y} R)$, determined in Lemma $\mathrm{H}$, solve after $\bar{y} / a$, and take the derivatives with respect to $R$ and $\beta \phi m$ :

$$
\begin{aligned}
\frac{\partial \bar{y} / a}{\partial R} & =-\frac{\beta a\left[\bar{q}^{T}-\beta \phi m\right]}{[\beta a R]^{2}}<0 \\
\frac{\partial \bar{y}}{\partial \beta \phi m} & =-\frac{1}{\beta R}<0 .
\end{aligned}
$$

\section{J. Proof of Lemma J}

As defined in Definition D and E, an equilibrium of the bargaining game is a 4-tuple $\left\{\left(p_{a}, y ; \kappa_{b}^{H}\right),\left(p_{a}, y ; \kappa_{b}^{L}\right), \mathcal{A}_{s}(\lambda), \lambda\right\}$, where $\left(p_{a}, y ; \kappa_{b}^{H}\right)$ is the equilibrium offer of a high-type buyer, $\left(p_{a}, y ; \kappa_{b}^{L}\right)$ the offer of a low-type buyer, $\mathcal{A}_{s}(\lambda)$ the seller's acceptance rule, and $\lambda$ the system of beliefs. Assuming that we only consider equilibria in which the offers are accepted, and alternative equilibrium $\left\{\left(p_{a}^{\prime}, y^{\prime} ; \kappa_{b}^{H}\right),\left(p_{a}^{\prime} y^{\prime} ; \kappa_{b}^{L}\right), \mathcal{A}_{s}(\lambda), \lambda\right\}$ defeats the original equilibrium if the following holds:

(a) For $\left(p_{a}, y ; \kappa_{b}^{H}\right) \neq\left(p_{a}, y ; \kappa_{b}^{L}\right)$ :

$$
u\left(\beta \phi\left(m+p_{a}^{H} y^{H}\right)\right)-\beta \phi\left(m+p_{a}^{H} y^{H}\right)<u\left(\beta \phi\left(m+p_{a}^{{ }^{H}} y^{\prime}{ }^{H}\right)\right)-\beta \phi\left(m+p_{a}^{\prime}{ }^{H} y^{\prime H}\right) .
$$

(b) For $\left(p_{a}, y ; \kappa_{b}^{H}\right)=\left(p_{a}, y ; \kappa_{b}^{L}\right)=\left(\bar{p}_{a}, \bar{y}\right)$ :

$$
\begin{array}{r}
u\left(\beta \phi\left(m+p_{a}^{H} y^{H}\right)\right)-\beta \phi\left(m+p_{a}^{H} y^{H}\right)<u\left(\beta \phi\left(m+p_{a}^{\prime}{ }^{\prime} y^{\prime H}\right)\right)-\beta \phi\left(m+p_{a}^{\prime}{ }^{H} y^{\prime H}\right) \\
\text { and } \quad u\left(\beta \phi\left(m+p_{a}^{L} y^{L}\right)\right)-\beta \phi\left(m+p_{a}^{L} y^{L}\right)<u\left(\beta \phi\left(m+p_{a}^{\prime L} y^{\prime L}\right)\right)-\beta \phi\left(m+p_{a}^{\prime L} y^{\prime L}\right),
\end{array}
$$

where (a) corresponds to the separating equilibrium, and (b) to the pooling. The alternative equilibrium defeats the original equilibrium in two cases. First, as summarized in (a), if there exists a profitable deviation for the high-type in the separating equilibrium, or second, 
in a pooling equilibrium (b), if both types have an incentive to deviate. If there is no such alternative equilibrium offer, the original equilibrium, determined in (30), (31) and (38), is undefeated.

\section{K. Proof of Proposition A}

The maximization problem of the high-type buyer, offering a separating contract in (31), has shown that his payoff is independent of the distribution of types, $\pi$. Contrary to that, in a pooling equilibrium, $\left(\bar{p}_{a}, \bar{y}\right)$, as determined in (38), the payoff of the high-type buyer is strictly decreasing in the amount of low-types in the economy, $\pi^{L}$.

Assuming the population only consists of high-types, i.e., $\pi^{H}=1$, then (31) corresponds to (38) with the difference that in the separating case the incentive compatibility constraint is binding. Given that, if $\pi^{H}=1$, it holds that $\bar{V}_{b}\left(m, a ; \kappa_{b}^{H}\right)>V_{b}\left(m, a ; \kappa_{b}^{H}\right)$. Considering now the case where there are only low-types in the economy, i.e., $\pi^{L}=1$, the following has to hold: $\bar{V}_{b}\left(m, a ; \kappa_{b}^{H}\right)<V_{b}\left(m, a ; \kappa_{b}^{H}\right)$.

Given that, there exists a threshold value, $\tilde{\pi}^{H} \in(0,1)$, such that the payoff of the hightype buyers in the separating and in the pooling equilibrium are equal, i.e., $\bar{V}_{b}\left(m, a ; \kappa_{b}^{H}\right)=$ $V_{b}\left(m, a ; \kappa_{b}^{H}\right)$. This then gives us the alternative conditions for the two equilibria: for all $\tilde{\pi}^{H}<\pi^{H}, \bar{V}_{b}\left(m, a ; \kappa_{b}^{H}\right)>V_{b}\left(m, a ; \kappa_{b}^{H}\right)$ and the equilibrium is pooling; and for all $\tilde{\pi}^{H}>\pi^{H}$, $\bar{V}_{b}\left(m, a ; \kappa_{b}^{H}\right)<V_{b}\left(m, a ; \kappa_{b}^{H}\right)$ and the equilibrium is separating.

\section{Proof of Lemma K}

To derive the equilibrium prices determined in Lemma $\mathrm{K},\left(\phi_{t}, \varphi_{t}\right)$, use the first-order conditions, (45) and (46), and plug in $S_{b, m}^{N}, S_{b, m}^{T}$ and $S_{b, a}^{T}$ with $S_{b}^{j}\left(m, a ; \kappa_{b}^{\chi}\right)=u\left[\beta \phi_{t+1} d^{j}\right]-\beta \phi_{t+1} d^{j}$ and $j \in\{N, T\}$.

\section{Proof of Proposition B}

To determine the equilibrium allocations for each region in Proposition B, use the equilibrium primary market prices determined in Lemma $\mathrm{K}$, and combine them with the equilibrium secondary- and goods market allocations determined in Lemma B.

\section{N. Proof of Lemma L}


Taking the derivative of $\mathcal{L}_{m}^{c}$ and $\mathcal{L}_{a}^{c}$, provided in Lemma $\mathrm{K}$, with respect to $\alpha$ and $n$ yields:

$$
\begin{aligned}
& \frac{\partial \mathcal{L}_{m}^{c}}{\partial \alpha}:(1-n)\left[\left[\pi^{L}\left[u\left(q^{T, L}\right)-1\right]+\pi^{H}\left[u\left(q^{T, H}\right)-1\right]\right]-\left[u\left(q^{N}\right)-1\right]\right]<0 \\
& \frac{\partial \mathcal{L}_{a}^{c}}{\partial \alpha}:(1-n)\left[\left[\frac{\pi^{L} \kappa^{L}}{R}\left[u\left(q^{T, L}\right)-1\right]+\frac{\pi^{H} \kappa^{H}}{R}\left[u\left(q^{T, H}\right)-1\right]\right]\right]>0 \\
& \frac{\partial \mathcal{L}_{m}^{c}}{\partial n}:-\left[\alpha\left[\pi^{L}\left[u\left(q^{T, L}\right)-1\right]+\pi^{H}\left[u\left(q^{T, H}\right)-1\right]\right]+(1-\alpha)\left[u\left(q^{N}\right)-1\right]\right]<0 \\
& \frac{\partial \mathcal{L}_{a}^{c}}{\partial n}:-\left[\alpha\left[\frac{\pi^{L} \kappa^{L}}{R}\left[u\left(q^{T, L}\right)-1\right]+\frac{\pi^{H} \kappa^{H}}{R}\left[u\left(q^{T, H}\right)-1\right]\right]\right]<0 .
\end{aligned}
$$

\section{O. Proof of Lemma M}

To derive the equilibrium prices determined in Lemma M, $\left(\phi_{t}, \varphi_{t}\right)$, use the first-order conditions, (45) and (46), and plug in $S_{b, m}^{N}, S_{b, m}^{T, L}, S_{b, m}^{T, H}, S_{b, a}^{T, L}$ and $S_{b, a}^{T, H}$ with $S_{b, m}$ and $S_{b, a}$ being the partial derivatives of the buyer's suplus function, $S_{b}^{T, \chi}\left(m, a ; \kappa_{b}^{\chi}\right)=u\left[\beta \phi_{t+1} d^{T, \chi}\right]-\beta \phi_{t+1} d^{T, \chi}$, with respect to $m$ and $a$, where $\chi \in\{L, H\}$.

\section{P. Proof of Proposition C}

To determine the equilibrium allocations for each region in Proposition $\mathrm{C}$, use the equilibrium primary market prices determined in Lemma $\mathrm{M}$, and combine them with the equilibrium secondary- and goods market allocations determined in (36), (37), and (42).

\section{Q. Proof of Proposition D}

This proof involves three steps. First, considering $\mathcal{L}_{m}^{S}$ and $\mathcal{L}_{m}^{P}$, one can see that $\mathcal{L}_{m}>0$, and thus $\phi_{t}>\phi_{t+1} \beta$, holds with strict inequality if $m<m^{*}$.

Second, considering $\mathcal{L}_{a}^{S}$ and $\mathcal{L}_{a}^{P}$, one can see that $\mathcal{L}_{a}^{S}>0$ if $\beta\left(\phi m+a \kappa^{L}\right)<q^{*}$ and $\mathcal{L}_{a}^{P}>0$ if $\beta(\phi m+a R)<q^{*}$.

Third, comparing $\mathcal{L}_{m}^{S}$ and $\mathcal{L}_{a}^{S}$, as well as $\mathcal{L}_{m}^{P}$ and $\mathcal{L}_{a}^{P}$, it emerges that $0 \leq \mathcal{L}_{a}<\mathcal{L}_{m}$ holds with strict inequality, if $\kappa^{L}<\kappa^{H}$ and $m<m^{*}$. 


\section{R. Proof of Proposition E}

This proof involves three steps:

First, it needs to be shown that $\frac{\partial \mathcal{L}_{m}}{\partial \beta \phi m}<0$ for $m<m^{*}$. From $\mathcal{L}_{m}^{S}$ we see that $u^{\prime}\left(q^{T, H}\right)>1$ if $m<m^{*}$ and thus $\frac{\partial \mathcal{L}_{m}^{S}}{\partial \beta \phi m}<0$, since an additional unit of money relaxes the agents' incentive compatibility constraint, (51). The same logic applies for $\mathcal{L}_{m}^{P}$.

Second, it needs to be shown that $\frac{\partial \mathcal{L}_{a}^{S}}{\partial \beta \phi m}<0$ for $\beta\left(\phi m+a \kappa^{L}\right)<q^{*}$, and $\frac{\partial \mathcal{L}_{a}^{P}}{\partial \beta \phi m}<0$ for $\beta(\phi m+a R)<q^{*}$. From $\mathcal{L}_{a}^{S}$ we see that $u^{\prime}\left(q^{T, L}\right)>1$ and $u^{\prime}\left(q^{T, H}\right)>1$ if $\beta\left(\phi m+a \kappa^{L}\right)<q^{*}$. Thus, $\frac{\partial \mathcal{L}_{a}^{S}}{\partial \beta \phi m}<0$, since an additional unit of fiat money relaxes the buyer's liquidity constraint. This holds for $\mathcal{L}_{a}^{P}$ as well, since $u^{\prime}(\bar{q})>1$ for $\beta(\phi m+a R)<q^{*}$.

Third, it needs to be shown that $\frac{\partial\left(\mathcal{L}_{m}-\mathcal{L}_{a}\right)}{\partial \beta \phi m}<0$ for $m<m^{*}$. From the first and the second part of the proof we know that the liquidity differential, $\mathcal{L}_{m}-\mathcal{L}_{a}$, is decreasing in $q^{T, L}, q^{T, H}$, and $\bar{q}$. Since $\frac{\partial q^{T, L}}{\partial \beta \phi m}>0$ if $\beta\left(\phi m+a \kappa^{L}\right)<q^{*}, \frac{\partial \bar{q}}{\partial \beta \phi m}>0$ if $\beta(\phi m+a R)<q^{*}$, and $\frac{\partial q^{T, H}}{\partial \beta \phi m}>0$ for all $m<m^{*}$, then $\frac{\partial\left(\mathcal{L}_{m}-\mathcal{L}_{a}\right)}{\partial \beta \phi m}<0$ for all $m<m^{*}$. 